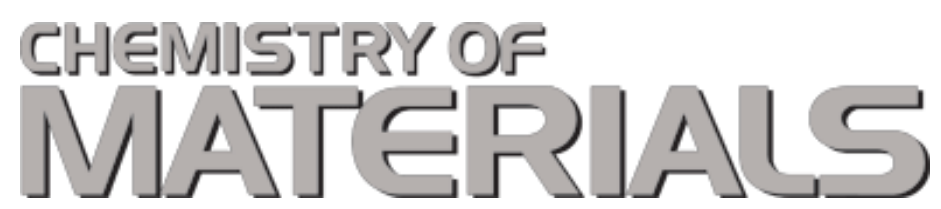

Subscriber access provided by JRD Tata Memorial Library | Indian Institute of Science

\title{
Article
}

\section{Influence of Cation Size on the Structural Features of LnAMnO Perovskites at Room Temperature}

P. M. Woodward, T. Vogt, D. E. Cox, A. Arulraj, C. N. R. Rao, P. Karen, and A. K. Cheetham

Chem. Mater., 1998, 10 (11), 3652-3665 • DOI: 10.1021/cm980397u

Downloaded from http://pubs.acs.org on February 6, 2009

\section{More About This Article}

Additional resources and features associated with this article are available within the HTML version:

- $\quad$ Supporting Information

- Links to the 16 articles that cite this article, as of the time of this article download

- Access to high resolution figures

- $\quad$ Links to articles and content related to this article

- $\quad$ Copyright permission to reproduce figures and/or text from this article

View the Full Text HTML 


\title{
Influence of Cation Size on the Structural Features of $\operatorname{Ln}_{1 / 2} \mathbf{A}_{1 / 2} \mathbf{M n O}_{3}$ Perovskites at Room Temperature
}

\author{
P. M. Woodward, ${ }^{*}, \dagger$ T. Vogt, ${ }^{\dagger}$ D. E. Cox, ${ }^{\dagger}$ A. Arulraj, ${ }^{\ddagger}$ C. N. R. Rao, ${ }^{\ddagger}$ \\ P. Karen, $\$$ and A. K. Cheetham \\ Physics Department, Brookhaven National Laboratory, Upton, New York 11973, \\ Solid State and Structural Chemistry Unit, Indian Institute of Science, \\ Bangal ore 560012, India, Department of Chemistry, University of Oslo, \\ P.O. Box 1033 Blindern, 0315 Oslo, Norway, and Materials Research Laboratory, \\ University of California, Santa Barbara, California 93106
}

Received J une 2, 1998. Revised Manuscript Received August 5, 1998

\begin{abstract}
Polycrystalline samples of $\mathrm{Ln}_{1 / 2} \mathrm{Sr}_{1 / 2} \mathrm{MnO}_{3}\left(\mathrm{Ln}=\mathrm{La}, \mathrm{Pr}, \mathrm{La}_{0.33} \mathrm{Nd}_{0.67}, \mathrm{Nd}, \mathrm{Nd}_{0.5} \mathrm{Sm}_{0.5}, \mathrm{Sm}\right.$, and $\mathrm{Gd}$ ) and $\mathrm{Ln}_{1 / 2} \mathrm{Ca}_{1 / 2} \mathrm{MnO}_{3}\left(\mathrm{Ln}=\mathrm{La}, \mathrm{Pr}, \mathrm{La}_{0.5} \mathrm{Nd}_{0.5}, \mathrm{Nd}, \mathrm{Sm}\right.$, and $\left.\mathrm{Y}_{0.5} \mathrm{Sm}_{0.5}\right)$ have been prepared, and structure determinations have been carried out at room temperature using high-resolution synchrotron X-ray powder diffraction data. The octahedral tilting distortion increases as the average ionic radius of the $\mathrm{Ln} / \mathrm{A}$ cations, $\left\langle\mathrm{r}_{\mathrm{A}}\right\rangle$, decreases. The two crystallographically distinct $\mathrm{Mn}-\mathrm{O}-\mathrm{Mn}$ bonds [ $\mathrm{Mn}-\mathrm{O}(\mathrm{eq})-\mathrm{Mn}$ and $\mathrm{Mn}-\mathrm{O}(\mathrm{ax})-\mathrm{Mn}$ ] are almost identical for $\mathrm{Ln}_{0.5} \mathrm{Ca}_{0.5} \mathrm{MnO}_{3}$ compounds, with the exception of $\mathrm{La}_{0.5} \mathrm{Ca}_{0.5} \mathrm{MnO}_{3}$. The $\mathrm{La}_{0.5} \mathrm{Ca}_{0.5} \mathrm{MnO}_{3}$ compound and the entire $\mathrm{Ln}_{0.5} \mathrm{Sr}_{0.5} \mathrm{MnO}_{3}$ series adopt structures where the $\mathrm{Mn}-\mathrm{O}(\mathrm{eq})-\mathrm{Mn}$ bond angle is consistently and significantly larger $\left(2-6^{\circ}\right)$ than the $\mathrm{Mn}-$ $\mathrm{O}(\mathrm{ax})-\mathrm{Mn}$ bond angle. All of the $\mathrm{Ln}_{0.5} \mathrm{Ca}_{0.5} \mathrm{MnO}_{3}$ compounds have Pnma symmetry, whereas across the $\mathrm{Ln}_{0.5} \mathrm{Sr}_{0.5} \mathrm{MnO}_{3}$ series with increasing $\left\langle\mathrm{r}_{\mathrm{A}}\right\rangle$, an evolution from Pnma (tilt system $a^{-} b^{+} a^{-}$) over I mma (tilt system $a^{-} b^{0} a^{-}$) to I $4 / m c m$ (tilt system $a^{0} a^{0} c^{-}$) symmetry is observed. It appears that the latter two tilt systems are stabilized with respect to the rhombohedral $\left(\mathrm{R} \overline{3}^{\mathrm{C}}\right) \mathrm{a}^{-} \mathrm{a}^{-} \mathrm{a}^{-}$tilt system, by short-range layered ordering of A-site cations. Changes in the octahedral tilt system at room temperature are linked to changes in the low-temperature magnetic structure. In particular, the simultaneous onset of charge ordering and CE-type antiferromagnetism in the $\mathrm{Ln}_{0.5} \mathrm{Sr}_{0.5} \mathrm{MnO}_{3}$ series appears to be closely associated with the I mma structure. The average $\mathrm{Mn}-\mathrm{O}$ bond distance is relatively constant across the entire series, but individual $\mathrm{Mn}-\mathrm{O}$ bond distances show the presence of a cooperative J ahn-Teller effect (orbital ordering) at room temperature in $\mathrm{Sm}_{0.5} \mathrm{Ca}_{0.5} \mathrm{MnO}_{3}$ and $\mathrm{Sm}_{0.25} \mathrm{Y}_{0.25} \mathrm{Ca}_{0.5} \mathrm{MnO}_{3}$.
\end{abstract}

\section{Introduction}

The magnetoresistive effect describes the phenomenon whereby the electrical resistivity of a solid changes upon application of a magnetic field. Interest in this effect, first observed by Kohler in $1938^{1}$ and later by Volger in the 1950s, ${ }^{2}$ was stimulated by the observation of large values of magnetoresistance (MR) in metallic multilayered thin films. ${ }^{3,4}$ Widespread interest in the chemistry, physics, and materials science communities was sparked when even larger values of MR were found in the $\mathrm{Ln}_{1-x} \mathrm{~A}_{x} \mathrm{MnO}_{3}$ perovskite system, where $\mathrm{A}$ is a divalent alkaline-earth cation and $L n$ is a trivalent lanthanide cation. The MR in these compounds was

* Current address of the corresponding author: Dept of Chemistry, The Ohio State University, 100 West 18th Ave, Columbus, OH 43210-1185.

† Brookhaven National Laboratory.

₹ Indian Institute of Science.

$\S$ University of Oslo.

"University of California.

(1) Kohler, M. Ann. Phys. 1938, 32, 211

(2) Volger, J . Physica (Utrecht) 1954, 20, 49.

(3) Baibich, M. N.; Broto, J. M.; Fert, A.; Nguyen Van Dau, F.; Petroff, F.; Etienne, P.; Creutzet, G.; Friederich, A.; Chazelas, J . Phys. Rev. Lett. 1988, 61, 2472.

(4) Parkin, S. S. P.; More, N.; Roche, K. P. Phys. Rev. Lett. 1990, 64, 2304. first observed in thin films, ${ }^{5-7}$ but later shown to occur in bulk samples. ${ }^{8,9}$ The change in resistivity in these compounds is so dramatic, nearly 6 orders of magnitude in optimized samples, ${ }^{10}$ that the term colossal magnetoresistance (CMR) was coined. N ot only are magnetic and electronic interactions intimately rel ated, but both effects are extremely sensitive to subtle structural changes. This delicate interplay between magnetism, transport properties, and structure leads to phase transitions that can be induced by varying the temperature, external pressure, ${ }^{11,12}$ chemical pressure, ${ }^{12-14}$ and external magnetic field. ${ }^{15,16}$

(5) Chahara, K.; Ohno, T.; Kasai, M.; Kozono, Y. Appl. Phys. Lett. 1993, 63, 1990

(6) J in, S.; McCormack, M.; Tiefel, T. H.; Ramesh, R. J . Appl. Phys. 1994, 76, 6929 .

(7) von Helmolt, R.; Wecker, J .; Samwer, K.; Haupt, L.; Bärner, K. J . Appl. Phys. 1994, 76, 6925.

(8) Ushibara, A.; M oritomo, Y.; Arima, T.; Asamitsu, A.; Kido, G.; Tokura, Y. Phys. Rev. B 1995, 51, 14103.

(9) Mahendiran, R.; Tiwary, S. K.; Raychaudhuri, A. K.; Ramakrishnan, T. V.; Mahesh, R.; Rangavittal, N.; Rao, C. N. R. Phys. Rev. B 1996, 53, 3348.

(10) Damay, F.; Maignan, A.; Nguyen, N.; Raveau, B. J . Solid State Chem. 1996, 124, 385.

(11) Moritomo, Y.; Kuwahara, H.; Tomioka, Y.; Tokura, Y. Phys. Rev. B 1997, 55, 7549.

(12) Hwang, H. Y.; Palstra, T. T. M.; Cheong, S.-W.; Batlogg, B. Phys. Rev. B 1995, 52, 15046. 
Table 1. Crystallographic and Magnetic Data for $\mathrm{LaMnO}_{3}$ and $\mathrm{CaMnO}_{3}$

\begin{tabular}{|c|c|c|c|c|c|c|}
\hline compound & space group & $\mathrm{Mn}-\mathrm{O}$ distances $(\AA)$ & $\mathrm{Mn}-\mathrm{O}-\mathrm{Mn}$ angles $\left({ }^{\circ}\right)$ & magnetic structure & $\mathrm{T}_{\mathrm{N}}(\mathrm{K})$ & manganese moment $\left(\mu_{\mathrm{B}}\right)$ \\
\hline $\mathrm{CaMnO}_{3}{ }^{72}$ & Pnma & $\begin{array}{l}2 \times 1.895(1) \\
2 \times 1.900(1) \\
2 \times 1.903(1)\end{array}$ & $\begin{array}{l}158.6(1) \\
157.2(1)\end{array}$ & G-type & 110 & 2.6 \\
\hline $\mathrm{LaMnO}_{3} 73$ & Pnma & $\begin{array}{l}2 \times 1.9680(3) \\
2 \times 1.907(1) \\
2 \times 2.178(1)\end{array}$ & $\begin{array}{l}155.48(2) \\
155.11(5)\end{array}$ & A-type & 100 & 3.9 \\
\hline
\end{tabular}

The prototypical end members of the $\mathrm{Ln}_{1-x} \mathrm{~A}_{x} \mathrm{MnO}_{3}$ perovskite system, $\mathrm{LaMnO}_{3}$ and $\mathrm{CaMnO}_{3}$, are both $\mathrm{Mott}$ insulators. They become antiferromagnetic near $100 \mathrm{~K}$, but adopt different spin arrangements ${ }^{17}$ (see Table 1). The manganese ions in $\mathrm{CaMnO}_{3}$ are tetravalent with electron configuration [Ar] $3 \mathrm{~d}^{3}$. The octahedral crystal field about manganese spl its the $3 d$ orbitals into a 3-fold degenerate $t_{2 g}$ set of orbitals, which are weakly $\pi$ antibonding, and a 2-fold degenerate $e_{\mathrm{g}}$ set, which are strongly $\sigma$ antibonding. ${ }^{18}$ Consequently, the $t_{2 g}$ orbitals are half filled in $\mathrm{CaMnO}_{3}$ and, due to superexchange interactions, ${ }^{19}$ a G-type antiferromagnetic spin arrangement (all nearest neighbor manganese ions coupled antiferromagnetically) $17,19,20$ is observed. In contrast, $\mathrm{LaMnO}_{3}$ contains trivalent manganese with electron configuration $[\mathrm{Ar}] 3 \mathrm{~d}^{4}$. Due to strong Hund's rule coupling, the manganese ions adopt a high spin configuration $\mathrm{t}_{2 \mathrm{~g}}{ }^{3} \mathrm{e}_{\mathrm{g}}{ }^{1}$. According to the J ahn-Teller (J T) theorem, a distortion of the local octahedral environment, removing the degeneracy of the $e_{g}$ orbitals, is energetically favorable. This distortion is accomplished by lengthening two of the $\mathrm{Mn}-\mathrm{O}$ bond trans to each other, which lowers the energy of the occupied $3 \mathrm{~d}_{z^{2}}$ orbitals, with respect to the empty $3 d_{x^{2}-y^{2}}$ orbitals. The filled $3 d_{z^{2}}$ orbitals form a zigzag pattern in the xy plane which leads to an expansion of the $a$ and $b$ unit cell dimensions. ${ }^{17,26}$ Superexchange interactions stabilize an Atype antiferromagnetic spin arrangement (ferromagnetic layers coupled antiferromagnetically to each other). ${ }^{17,19,20}$

The manganese $e_{g}$ orbitals overlap with the oxygen $2 \mathrm{p} \sigma$ orbitals to form $\sigma$ and $\sigma^{*}$ bands. Because the highest energy electrons reside in the $\sigma^{*}$ band, which is primarily $\mathrm{Mn} \mathrm{e}_{\mathrm{g}}$ in character, changes in its energy level, filling, and width can have a dramatic impact on the magnetic and electrical transport behavior of these materials. In $\mathrm{CaMnO}_{3}$, this band is empty and consequently insulating behavior is observed. This band is $1 / 4$ filled in $\mathrm{LaMnO}_{3}$ (the spin-up component is $1 / 2$ filled), but the cooperative J T distortion splits the $\sigma^{*}$ band, lowering the energy of the occupied orbitals. This results in a localization of carriers, and thus $\mathrm{LaMnO}_{3}$ is a semiconductor, with a band gap of approximately $0.7 \mathrm{eV} .^{21}$

The physical properties and phase transitions of $\mathrm{Ln}_{1-x} \mathrm{~A}_{x} \mathrm{MnO}_{3}$ compounds are considerably more complex than the end members. Because there is now a mixture of $\mathrm{Mn}^{3+}$ and $\mathrm{Mn}^{4+}$, the cooperative J T lattice

(13) Hwang, H. Y.; Cheong, S.-W.; Radaelli, P. G.; Marezio, M.; Batlogg, B. Phys. Rev. Lett. 1995, 75, 914.

(14) Mahesh, R.; Mahendiran, R.; Raychaudhuri, A. K.; Rao, C. N. R. J . Solid State Chem. 1995, 120, 204.

(15) Asamitsu, A.; Moritomo, Y.: Tomioka, Y.; Arima, T.; Tokura, Y. Nature 1995, 373, 407.

(16) Kuwahara, H.; Tomioka, Y.; Asamitsu, A.; Moritomo, Y.; Tokura, Y. Science 1995, 270, 961.

(17) Wollan, E. O.; Koehler, W. C. Phys. Rev. 1955, 100, 545. distortions are either frustrated or must adopt new ordered arrangements. Suppression of the cooperative $\mathrm{J} \mathrm{T}$ distortion reduces the splitting of the $\sigma^{*}$ band and can lead to a delocalization of the carriers. Carrier delocalization is further enhanced by a ferromagnetic alignment of localized $t_{2 g}$ and itinerant $e_{g}$ electrons. Such an arrangement is necessary to maintain the Hund's rule coupling and all ow the $e_{g}$ electrons to move freely through the lattice. The simultaneous stabilization of ferromagnetism and metallic conductivity is explained by the double-exchange interaction.22-24 For $\mathrm{La}_{1-x} \mathrm{Ca}_{x} \mathrm{MnO}_{3}$, the ferromagnetic metal Iic (FMM) state exists as the ground state for $0.17<\mathrm{x}<0.5 .25$

There are two antiferromagnetic (AFM) states that compete with the FMM state. The first of these is the CE-type structure first proposed by Goodenough. ${ }^{26}$ Localized carriers, high resistivity, long-range $\mathrm{Mn}^{3+}$ / $\mathrm{Mn}^{4+}$ charge ordering, cooperative ordering of the occupied $\mathrm{Mn}^{3+} \mathrm{e}_{\mathrm{g}}$ orbitals (orbital ordering), and a complex superexchange stabilized antiferromagnetic spin arrangement are all characteristics of the AFMCE state. Recent structural studies of $\mathrm{La}_{0.5} \mathrm{Ca}_{0.5} \mathrm{MnO}_{3}{ }^{27}$ and $\mathrm{Nd}_{0.5} \mathrm{Sr}_{0.5} \mathrm{MnO}_{3}{ }^{28}$ have confirmed the simultaneous presence of charge order, orbital order, and antiferromagnetic order in the AFM-CE state. Because of the 1:1 ordering of $\mathrm{Mn}^{3+} / \mathrm{Mn}^{4+}$ the AFM-CE state is most stable for doping levels near $\mathrm{x}=0.5$.

The final ground state of interest is the AFM-A type structure, which contains ferromagnetic layers, coupled antiferromagnetically to each other. ${ }^{17,19,20,26}$ The occupied $e_{g}$ orbitals are spatially confined within the FM layers. Traditionally, stabilization of the AFM-A type structure has been attributed to superexchange interactions within a lattice containing localized and orbitally ordered $\mathrm{Mn} \mathrm{e}_{\mathrm{g}}$ electrons. ${ }^{26}$ However, recent theoretical calculations ${ }^{21}$ and experimental observations ${ }^{29}$ have shown that metallic conductivity within the FM layers can also lead to a stabilization of the AFM-A type structure. This result is in contrast to the AFM-CE

(18) Due to the octahedral tilting distortion, orthorhombic rather than cubic symmetry is observed so that the $t_{2 g}$ and $e_{g}$ descriptors are not strictly valid, but they represent the actual splitting of the d-orbitals to a good approximation.

(19) Goodenough, J. B. Magnetism and the Chemical Bond, Interscience \& Wiley: New York, 1963.

(20) Cox, D. E. IEEE Trans. Magn. 1972, 8, 161

(21) Solovyev, I.; Hamada, N.; Terakura, K. Phys. Rev. Lett. 1996, 76,4825 .

(22) Zener, C. Phys. Rev. 1951, 82, 403

(23) deGennes, P. G. Phys. Rev. 1960, 118, 141

(24) Anderson, P. W.; Hasegawa, H. Phys. Rev. 1955, 100, 675.

(25) Cheong, S.-W.; Hwang, H. Y. Colossal Magnetoresistance Oxides: Tokura, Y. ed.; Gordon \& Breach: New York, 1998.

(26) Goodenough, J. B. Phys. Rev. 1955, 100, 564.

(27) Radaelli, P. G.; Cox, D. E.; Marezio, M.; Cheong, S.-W. Phys. Rev. B 1997, 55, 3015.

(28) Woodward, P. M.; Cox, D. E.; Vogt, T. submitted for publication in $\mathrm{J}$. Supercond.

(29) Akimoto, T.; Maruyama, Y.; Moritomo, Y.; Nakamura, A.; Hirota, K.; Ohoyama, K.; Ohashi, M. Phys. Rev. B 1998, 57, R5594. 
state, which cannot be maintained in the presence of delocalized carrier transport. Another distinction between AFM-A and AFM-CE states is the fact that $\mathrm{Mn}^{3+}$ / $\mathrm{Mn}^{4+}$ charge ordering has never been observed in conjunction with AFM-A type magnetic ordering. These last two points suggest that, at least for doping levels near $x=0.5$, the $e_{g}$ electrons in the AFM-A state are confined within the FM layers, but unlike the AFM-CE state they are not completely local ized.

The discussion up to this point has concentrated on the highly correlated nature of the electronic and magnetic properties. The importance of the doping level, $x$, has been alluded to in the preceding paragraphs, but structure-property relationships have thus far been ignored. However, it is well known that for a given value of $x$, the phase transition temperatures and physical properties can vary dramatically with changes in the ionic radi $i$ of the $L \mathrm{n} / \mathrm{A}$ cations. ${ }^{11,13,30-34}$ Figure 1 shows the phase diagrams for $\mathrm{Ln}_{0.5} \mathrm{Sr}_{0.5} \mathrm{MnO}_{3}$ and $\mathrm{Ln}_{0.5} \mathrm{Ca}_{0.5} \mathrm{MnO}_{3}$ as a function of the average radius of the $L n / A$ cations, $\left\langle r_{A}\right\rangle=\left(r_{A}+r_{L n}\right) / 2$. From this figure one can clearly see that the phase transition behavior and ground state identity of these materials is remarkably sensitive to changes in the identity and size of the $\mathrm{Ln} / \mathrm{A}$ cations. The delicate competition between $\mathrm{FMM}$, AFM-A, and AFM-CE states is also evident.

What is the origin of the extreme sensitivity these compounds display to small changes in $\left\langle r_{A}\right\rangle$ ? The effect is generally attributed to an increased tilting of the $\mathrm{MnO}_{6}$ octahedra as $\left\langle\mathrm{r}_{\mathrm{A}}\right\rangle$ decreases. Octahedral tilting distortions, where the octahedra remain essentially rigid while the $\mathrm{Mn}-\mathrm{O}-\mathrm{Mn}$ angles distort, are commonly observed among perovskites. ${ }^{35}$ Because they decrease the nearest neighbor $\mathrm{A}-\mathrm{O}$ distances without perturbing the $\mathrm{Mn}-\mathrm{O}$ distances, they allow the structure to optimize the largely ionic $\mathrm{A}-\mathrm{O}$ bonding without diminishing the more strongly coval ent $\mathrm{Mn}-\mathrm{O}$ bonding. The relationship between octahedral tilting and the physical properties can be understood in the following manner. Decreasing $\left\langle\mathrm{r}_{\mathrm{A}}\right\rangle$ leads to a decrease in the $\mathrm{Mn}-\mathrm{O}-\mathrm{Mn}$ angles, $\alpha=180^{\circ}-\omega$. This decrease in turn decreases the spatial overlap of the $\mathrm{Mn} \mathrm{e}_{\mathrm{g}}$ and $\mathrm{O} 2 \mathrm{p} \sigma$ orbitals, and consequently the $\sigma^{*}$ bandwidth, W, is reduced. Quantitatively, it has been shown that W is directly proportional to $\cos \omega \cdot{ }^{36,37}$ Decreasing $\mathrm{W}$ reduces the carrier mobility, thereby destabilizing the FMM state (notice the rapid decrease in $T_{C}$ with decreasing $\left\langle r_{A}\right\rangle$ in Figure 1 ), as well as decreasing the strength of the antiferromagnetic superexchange interactions. On the other hand, decreasing W will encourage carrier localization, which will stabilize orbital and charge ordering.

Although the picture just described can qualitatively explain certain trends in Figure 1, it is too simple to

(30) Fontcuberta, J .; Martínez, B.; Seffar, A.; Piñol, S.; GarcíaMunoz, J. L.; Obradors, X. Phys. Rev. Lett. 1996, 76, 1122.

(31) Fontcuberta, J .; Garcia-Muñoz, J . L.; Suaaidi, M.; Martinez, B.; Piñol, S.; Obradors, X. J . Appl. Phys. 1997, 81, 5481.

(32) Kuwahara, H.; Moritomo, Y.; Tomioka, Y.; Asamitsu, A.; Kasai M.; Kumai, R.; Tokura, Y. Phys. Rev. B 1997, 56, 9386.

(33) Sundaresan, A.; Paulose, P. L.; Malik, R.; Sampathkumaran,

E. V. Phys. Rev. B 1998, 57, 2690.

(34) Radaelli, P. G.; Iannone, G.; Marezio, M.; Hwang, H. Y.; Cheong, S.-W.; J orgensen, J. D.; Argyriou, D. N. Phys. Rev. B, in press.

(35) Woodward, P. M. Acta Crystallogr. 1997, B53, 44.

(36) Töpfer, J .; Goodenough, J . B. J . Solid State Chem. 1997, 130, 117.

(37) Medarde, M.; Mesot, J .; Lacorre, P.; Rosenkranz, S.; Fischer, P.; Gobrecht, K. Phys. Rev. B 1995, 52, 9248.
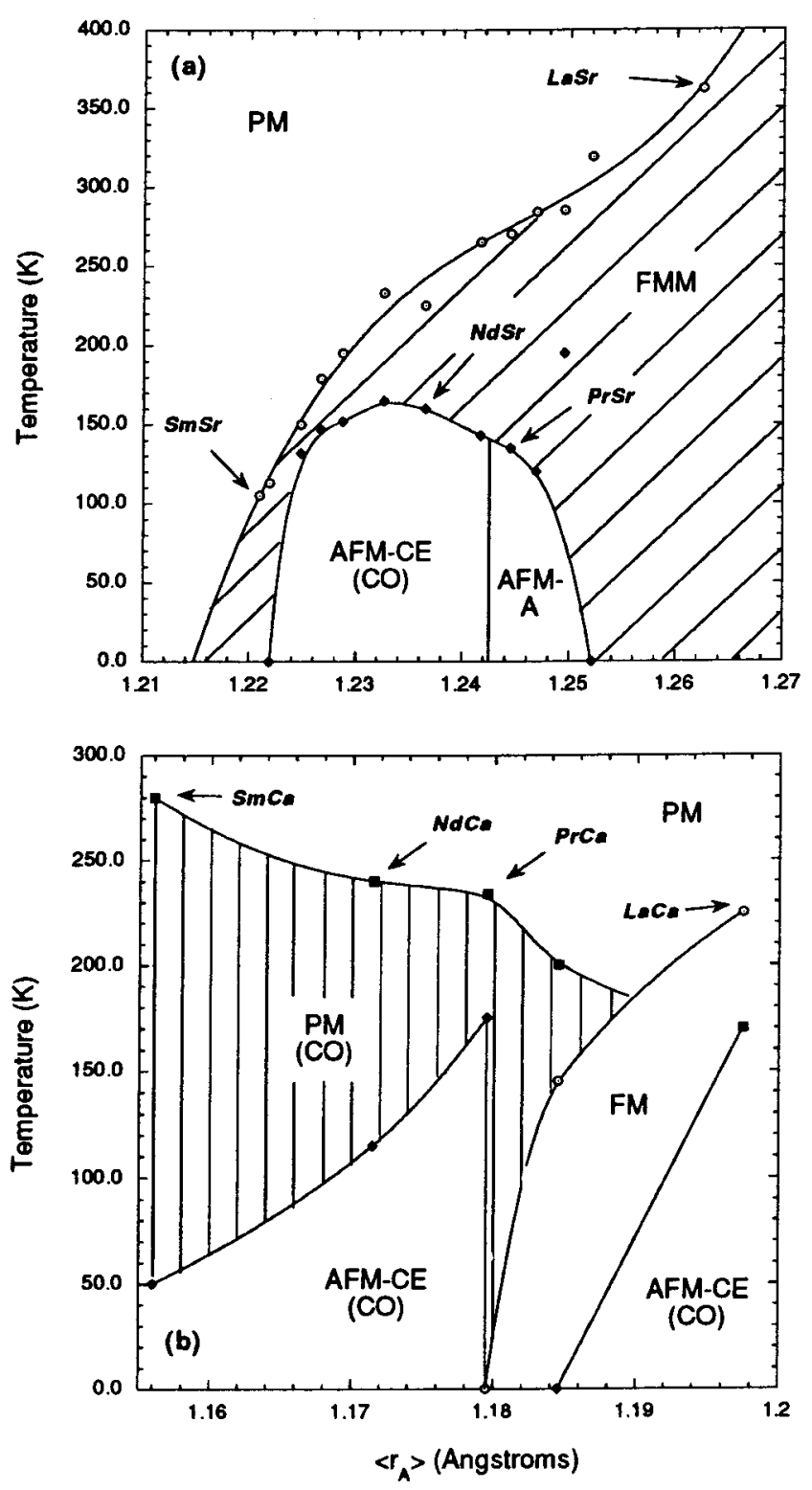

Figure 1. Phase diagram for (a) $\mathrm{Ln}_{0.5} \mathrm{Sr}_{0.5} \mathrm{MnO}_{3}$ and (b) $\mathrm{Ln}_{0.5^{-}}$ $\mathrm{Ca}_{0.5} \mathrm{MnO}_{3}$ compositions as a function of $\left\langle\mathrm{r}_{\mathrm{A}}\right\rangle$. The open circles represent the Curie temperature, $T_{C}$, the filled diamonds the Néel temperature, $T_{N}$, and in part (b) the filled squares represent the charge-ordering temperature, $\mathrm{T}_{\mathrm{co}}$. Phase transition temperatures were inferred from magnetization and transport measurements reported in refs $11,32,42,45$, and 77-79, and magnetization measurements made on the samples discussed in this paper (to be published at a later date).

explain many features of the phase diagram. Furthermore, there are several key assumptions implied when physical properties are related directly to $\left\langle r_{A}\right\rangle$. First of all, Ln/A cations are assumed to be randomly distributed and to act as a "virtual" ion with a single radius, $\left\langle r_{A}\right\rangle$. Second, the $\mathrm{Mn}-\mathrm{O}-\mathrm{Mn}$ angles are assumed to decrease proportionally with $\left\langle r_{A}\right\rangle$ and to be isotropic. Finally, the average $\mathrm{Mn}-\mathrm{O}$ distance is presumed to be independent of $\left\langle r_{A}\right\rangle$. Rodriguez-Martinez and Attfield have shown that for a constant $x$ and $\left\langle r_{A}\right\rangle, T_{C}$ is quite sensitive to the radius mismatch of the $\mathrm{Ln} / \mathrm{A}$ cations, ${ }^{38}$ whereas Fontcuberta et al. have observed that for a given $\left\langle r_{A}\right\rangle$, the Curie temperature is lower when $A=S r$ than when $A=\mathrm{Ca}^{31}$ Both findings are in direct contradiction to the first assumption. However, in 
neither case was the relationship between the Ln/A radius mismatch and the crystal structure investigated. Radaelli et al. have studied the structures of several $\mathrm{Ln}_{0.7} \mathrm{~A}_{0.3} \mathrm{MnO}_{3}$ compounds and found the second and third assumptions to be only approximately valid.34 Because the phase diagram for $x=0.5$ is considerably more complicated than for $\mathrm{x}=0.3$, we felt a systematic structural study of $\mathrm{Ln}_{0.5} \mathrm{~A}_{0.5} \mathrm{MnO}_{3}$ compounds would represent a significant contribution to the CMR literature. The results of this study not only examine the validity of the aforementioned assumptions, they also reveal a striking correlation between changes in the octahedral tilt system at room temperature and changes in the magnetic structure (FMM , AFM-A, and AFM-CE) at low temperature.

\section{Experimental Section}

Samples were prepared in air from stoichiometric quantities of $\mathrm{SrCO}_{3}, \mathrm{CaCO}_{3}, \mathrm{Ln}_{2} \mathrm{O}_{3}(\mathrm{Ln}=\mathrm{La}, \mathrm{Nd}, \mathrm{Sm}, \mathrm{Gd}, \mathrm{Y}), \mathrm{Pr}_{6} \mathrm{O}_{11}$, and $\mathrm{MnO}$ using conventional ceramic synthesis techniques. $\mathrm{La}_{2} \mathrm{O}_{3}$ was dried at $950{ }^{\circ} \mathrm{C}$ and stored in a desiccator prior to weighing to remove adsorbed water and $\mathrm{CO}_{2}$. I nitial annealing cycles were carried out in the $1000-1200^{\circ} \mathrm{C}$ range, and final heat treatments of 6-18 $\mathrm{h}$ were performed near the melting point of each compound $\left(1450-1510{ }^{\circ} \mathrm{C}\right.$, except for $\mathrm{Gd}_{0.5} \mathrm{Sr}_{0.5}$ $\mathrm{MnO}_{3}$, which had to be annealed at $1360^{\circ} \mathrm{C}$ to avoid melting). Samples were cooled in the furnace over a period of 2-4 $\mathrm{h}$.

High-resolution synchrotron X-ray powder diffraction data were collected on the X7A beamline at the National Synchrotron Light Source at Brookhaven National Laboratory. Monochromatic radiation was obtained from a channel-cut doublecrystal Si (111) monochromator, oriented to give a wavelength of $0.8016 \AA$. The samples were loaded into glass capillaries (diameter $\approx 0.2 \mathrm{~mm})$, which were freely rotated $(1-2 \mathrm{~Hz})$ during data collection to reduce any possible preferred orientation effects. The sample density was measured when filling the capillary and used to correct the data for absorption. A linear position-sensitive detector (PSD) ${ }^{39}$ was employed. Data collection times were typically $4 \mathrm{~h}$ per sample.

The excellent signal-to-noise ratio and resolution of the X7A diffractometer allow the detection of sample inhomogeneities and impurity phases at a level where they cannot be detected using a conventional X-ray or a neutron diffractometer. Under these stringent analysis conditions $\mathrm{Nd}_{0.5} \mathrm{Sr}_{0.5} \mathrm{MnO}_{3}, \mathrm{Nd}_{0.25}$ $\mathrm{Sm}_{0.25} \mathrm{Sr}_{0.5} \mathrm{MnO}_{3}$, and $\mathrm{Ln}_{0.5} \mathrm{Ca}_{0.5} \mathrm{MnO}_{3}(\mathrm{Ln}=\mathrm{La}, \mathrm{Pr}, \mathrm{Nd}$, and $\mathrm{Sm}$ ) were found to be single phase, whereas $\mathrm{Gd}_{1 / 2} \mathrm{Sr}_{1 / 2} \mathrm{MnO}_{3}$ $\mathrm{Sm}_{1 / 2} \mathrm{Sr}_{1 / 2} \mathrm{MnO}_{3}, \mathrm{La}_{1 / 4} \mathrm{Nd}_{1 / 4} \mathrm{Ca}_{1 / 2} \mathrm{MnO}_{3}$, and $\mathrm{Y}_{1 / 4} \mathrm{Sm}_{1 / 4} \mathrm{Ca}_{1 / 2} \mathrm{MnO}_{3}$ all contained trace amounts of impurity phases. The intensities of the strongest impurity reflections were typically $0.1-$ $0.5 \%$ of the intensity of the strongest perovskite reflection; thus, the identification of the impurity phases was not attempted. $\mathrm{La}_{0.5} \mathrm{Sr}_{0.5} \mathrm{MnO}_{3}, \mathrm{La}_{0.17} \mathrm{Nd}_{0.33} \mathrm{Sr}_{0.5} \mathrm{MnO}_{3}$, and $\mathrm{Pr}_{0.5} \mathrm{Sr}_{0.5^{-}}$ $\mathrm{MnO}_{3}$ were found to be two-phase mixtures of orthorhombic and tetragonal perovskite structures as discussed in more detail in the Results Section. I mpurity phases were not found to be present in the latter three samples. Structural refinements were performed using the Rietveld method as implemented in the GSAS software suite. ${ }^{40}$ In addition to the absorption correction al ready mentioned, corrections for anomalous dispersion were also made. A linear interpolation of fixed points was used to model the background.

The oxygen content of our samples was determined iodometrically. Finely powdered samples were dissolved under ultrasound in titration flasks filled with an Ar atmosphere.

(38) Rodriguez-Martinez, L.; Attfield, J . P. Phys. Rev B 1996, 54, 15622.

(39) Smith, G. C. Synchr. Rad. News 1991, 4, 24.

(40) Larson, A. C.; Von Dreele, R. B. GSAS: General Structural Analysis System, LANSCE, Los Alamos National Laboratory: Los Alamos, NM, 1994.

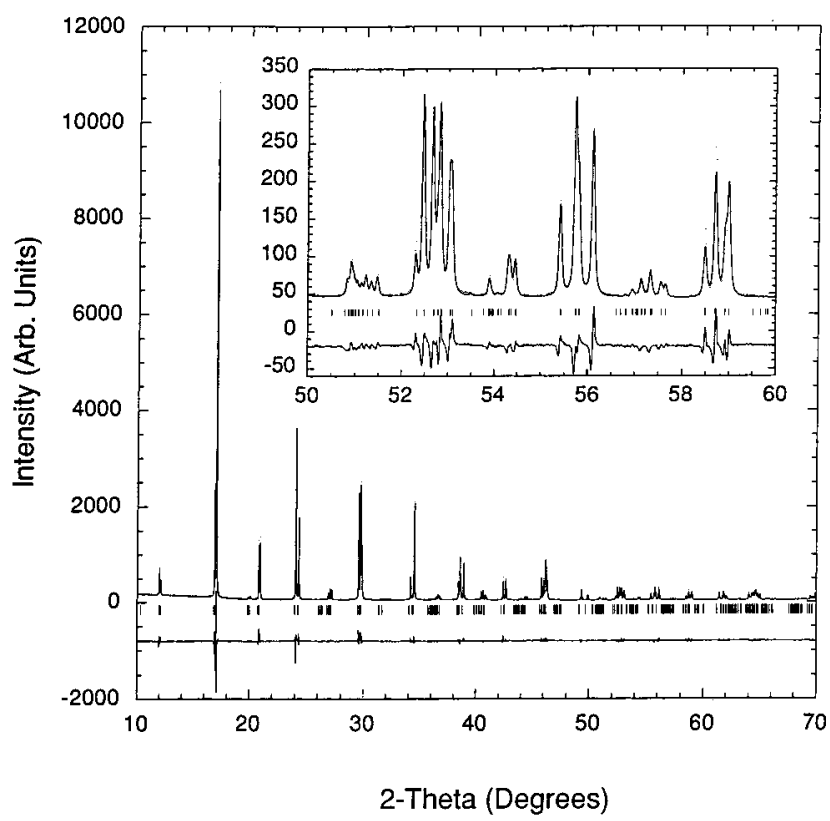

Figure 2. Rietveld refinement results for $\mathrm{Nd}_{0.5} \mathrm{Sr}_{0.5} \mathrm{MnO}_{3}$. The experimental data points are shown as dots, and the calculated fit and difference curve are shown as solid lines. Tick marks indicate the calculated reflection positions. A portion of the high angle region $\left(50^{\circ}<2 \theta<60^{\circ}\right)$ is magnified.

Digestions were carried out in solutions containing $4 \mathrm{~mL}$ of concentrated hydrochloric acid, $1 \mathrm{~g}$ of potassium iodide, and 5 $\mathrm{mL}$ water, and typically lasted $5 \mathrm{~s}$ for $0.10-\mathrm{g}$ samples containing $\mathrm{Sr}$ and around $30 \mathrm{~s}$ for samples containing $\mathrm{Ca}$. After dilution with water, the newly formed triodide soluti ons were titrated with $0.1 \mathrm{M}$ thiosulfate solution. The molarity of the thiosulfate solution was calculated from titrations of $\mathrm{KIO}_{3}$ (analytical standard grade quality). Close to the equivalence point, soluble starch was added as an indicator. Blank analyses were performed and showed essentially no oxidation $(<1 / 500$ of the oxidation due to the sample).

\section{Results}

Figure 2 shows the observed pattern and the refined fit to the $\mathrm{Nd}_{0.5} \mathrm{Sr}_{0.5} \mathrm{MnO}_{3}$ diffraction data. The inset shows that even at higher angles, the counting statistics and peak resolution are good enough to extract considerable information from the pattern. The combination of excellent counting statistics, high resolution, and the large number of observed reflections (typically 250-500 reflections for 19-20 variables) results in structural refinements that are of a much higher accuracy than can typically be achieved using conventional X-ray diffraction data. In the most favorable cases, the accuracy of these refinements is comparable to the accuracy that could be obtained from high-resolution neutron diffraction data. However, for certain compositions, lattice strain (which broadens the high angle peaks) and psuedo-cubic symmetry lead to significant peak overlap, which reduces the precision of the refinement. Tables 2-4 list the refinement statistics, unit cell parameters, space groups, and lattice strain as determined from the Rietveld refinements. Changes in the space group are a consequence of changes in the octahedral tilt system. A detailed description and examination of each type of octahedral tilting encountered in these compounds is given in the Discussion section. The fractional coordinates and displacement parameters 
Table 2. Refinement Statistics, Unit Cell Dimensions, and Microstrain Parameters for $\mathrm{Ln}_{0.5} \mathrm{Sr}_{0.5} \mathrm{MnO}_{3} \mathrm{Compounds}(\mathrm{Ln}=$ La, La/Nd, Pr)

\begin{tabular}{|c|c|c|c|c|c|c|}
\hline Ianthanide & \multicolumn{2}{|c|}{ La } & \multicolumn{2}{|c|}{$\mathrm{La}_{0.33} \mathrm{Nd}_{0.67}$} & \multicolumn{2}{|c|}{$\operatorname{Pr}$} \\
\hline $\mathrm{R}_{\mathrm{wp}}$ & \multicolumn{2}{|c|}{$5.28 \%$} & \multicolumn{2}{|c|}{$7.87 \%$} & \multicolumn{2}{|c|}{$7.18 \%$} \\
\hline $\mathrm{RP}_{\mathrm{P}}$ & \multirow{2}{*}{\multicolumn{2}{|c|}{$\begin{array}{l}3.44 \% \\
5.69 \%\end{array}$}} & \multicolumn{2}{|c|}{$5.53 \%$} & \multicolumn{2}{|c|}{$5.09 \%$} \\
\hline$R\left(F^{2}\right)$ & & & \multicolumn{2}{|c|}{$6.11 \%$} & \multicolumn{2}{|c|}{$5.21 \%$} \\
\hline $2 \theta$ Range & \multicolumn{2}{|c|}{$9-67^{\circ}$} & \multirow{2}{*}{\multicolumn{2}{|c|}{$\begin{array}{c}9-72^{\circ} \\
357\end{array}$}} & \multirow{2}{*}{\multicolumn{2}{|c|}{$9-72^{\circ}$}} \\
\hline \# reflections & \multicolumn{2}{|c|}{313} & & & & \\
\hline \#variables & \multicolumn{2}{|c|}{18} & \multicolumn{2}{|c|}{19} & \multicolumn{2}{|c|}{$\begin{array}{c}361 \\
18\end{array}$} \\
\hline space group & |4/mcm & Imma & I4/mcm & Imma & 14/mcm & Imma \\
\hline mass fraction & $60.6(6) \%$ & $39.4 \%$ & $13.0(3) \%$ & $87.0 \%$ & $85.3(2) \%$ & $14.7 \%$ \\
\hline$a(\AA)$ & $5.44247(3)$ & $5.4608(2)$ & $5.4016(2)$ & $5.43844(7)$ & $5.40278(3)$ & $5.4413(3)$ \\
\hline$b(\AA)$ & - & $7.6980(2)$ & - & $7.6477(1)$ & - & $7.6522(4)$ \\
\hline$c(\AA)$ & $7.76613(6)$ & $5.4792(2)$ & $7.7732(4)$ & $5.47610(7)$ & $7.78744(5)$ & $5.4791(3)$ \\
\hline volume $\left(\AA^{3}\right)$ & $230.036(3)$ & $230.330(8)$ & 226.81(1) & 227.759(6) & 227.316(3) & $228.14(1)$ \\
\hline strain ${ }^{74}$ (Gauss) & $0.091 \%$ & $0.091 \%$ & $0.119 \%$ & $0.119 \%$ & $0.089 \%$ & $0.089 \%$ \\
\hline strain $^{74}$ (Lorentz) & $0.016 \%$ & $0.210 \%$ & $0.024 \%$ & $0.024 \%$ & $0.011 \%$ & $0.147 \%$ \\
\hline
\end{tabular}

Table 3. Refinement Statistics, Unit Cell Dimensions, and Microstrain Parameters for $\mathrm{Ln}_{0.5} \mathrm{Sr}_{0.5} \mathrm{MnO}_{3}$ Compounds ( $\mathbf{L n}=\mathbf{N d}, \mathbf{N d} / \mathrm{Sm}, \mathrm{Sm}, \mathbf{G d})$

\begin{tabular}{lllll}
\hline \multicolumn{1}{c}{ lanthanide } & \multicolumn{1}{c}{$\mathrm{Nd}$} & $\mathrm{Nd}_{0.5} \mathrm{Sm}_{0.5}$ & \multicolumn{1}{c}{$\mathrm{Sm}$} & \multicolumn{1}{c}{$\mathrm{Gd}$} \\
\hline $\mathrm{R}_{\mathrm{wp}}$ & $7.23 \%$ & $5.09 \%$ & $6.28 \%$ & $6.00 \%$ \\
$\mathrm{R}_{\mathrm{p}}$ & $4.65 \%$ & $3.33 \%$ & $3.95 \%$ & $4.04 \%$ \\
$\mathrm{R}\left(\mathrm{F}^{2}\right)$ & $6.80 \%$ & $5.88 \%$ & $5.90 \%$ & $4.48 \%$ \\
$2 \theta$ range & $10-82^{\circ}$ & $9-82^{\circ}$ & $8-62^{\circ}$ & $10-65^{\circ}$ \\
\# reflections & 312 & 317 & 290 & 361 \\
\# variables & 15 & 15 & 20 & 20 \\
space group & $\mathrm{Imma}$ & $\mathrm{Imma}$ & $\mathrm{Pnma}$ & $\mathrm{Pnma}$ \\
$\mathrm{a}(\AA)$ & $5.43153(3)$ & $5.42352(3)$ & $5.41986(5)$ & $5.4222(2)$ \\
$\mathrm{b}(\AA)$ & $7.63347(4)$ & $7.62476(4)$ & $7.63856(7)$ & $7.6422(1)$ \\
$\mathrm{C}(\AA)$ & $5.47596(3)$ & $5.46335(3)$ & $5.44733(5)$ & $5.4229(2)$ \\
volume $\left(\AA^{3}\right)$ & $227.041(2)$ & $225.927(3)$ & $225.519(4)$ & $224.710(6)$ \\
strain 74 (Gauss) & $0.038 \%$ & $0.059 \%$ & $0.074 \%$ & $0.096 \%$ \\
strain $^{74}$ (Lorentz) & $0.053 \%$ & $0.033 \%$ & $0.057 \%$ & $0.134 \%$
\end{tabular}

are contained in Tables 5-7. Key structural parameters are tabulated in Tables 8 and 9 , and Table 10 contains the iodometric titration results. The Ln/A site occupancy was refined to check for deviations in the cation stoichiometry, but the refined occupancies were found to be consistently within $1 \%$ of the expected value, and therefore, cation occupancies were fixed to the stoichiometric ratios to avoid correlation with the displacement parameters. The refinement and titration results taken together show that the samples investigated in this study are highly crystalline, homogeneous, and very close to the intended $\mathrm{Ln}_{0.5} \mathrm{~A}_{0.5} \mathrm{MnO}_{3}$ stoichiometry.

Structural data has been previously reported for $\mathrm{Nd}_{0.5-}$ $\mathrm{Sr}_{0.5} \mathrm{MnO}_{3}{ }^{, 11} \mathrm{Pr}_{0.5} \mathrm{Sr}_{0.5} \mathrm{MnO}_{3},{ }^{42,43} \mathrm{La}_{0.5} \mathrm{Ca}_{0.5} \mathrm{MnO}_{3},{ }^{27,33} \mathrm{Nd}_{0.5-}$ $\mathrm{Ca}_{0.5} \mathrm{MnO}_{3},{ }^{44} \mathrm{Pr}_{0.5} \mathrm{Ca}_{0.5} \mathrm{MnO}_{3},{ }^{45}$ and $\mathrm{La}_{0.5} \mathrm{Sr}_{0.5} \mathrm{MnO}_{3} .^{33}$ Our results are in excellent agreement with the previously reported structures for the first two compounds, which were determined based on refinements of neutron diffraction data. For $\mathrm{La}_{0.5} \mathrm{Ca}_{0.5} \mathrm{MnO}_{3}$, good agreement is obtained between the results obtained in this study and the previously reported results (also based on neutron data); however, the lattice constants reported previously are consistently larger than we observe, resulting in a $0.4 \%$ increase in the unit cell volume. The

(41) Caignaert, V.; Millange, F.; Hervieu, M.; Suard, E.; Raveau, B. Solid State Comm. 1996, 99, 173.

(42) Damay, F.; Martin, C.; Hervieu, M.; Maignan, A.; Raveau, B.; Andre, G.; Bouree, F. J . Magn. Magn. Mater. 1998, 184, 71.

(43) Argyriou, D. N.; Hinks, D. G.; Mitchell, J . F.; Potter, C. D.; Schulz, A. J.; Young, D. M.; J orgensen, J . D.; Bader, S. D. J . Solid State Chem. 1996, 124, 381.

(44) Kobayashi, T.; Takizawa, H.; Endo, T.; Sato, T.; Shimada, M.; Taguchi, H.; Nagao, M. J. Solid State Chem. 1991, 92, 116.

(45) J irak, Z.; Krupicka, S.; Simsa, Z.; Dlouha, M.; Vratislav, S. J . Magn. Magn. Mater. 1985, 53, 153.

origin of this discrepancy is unknown, but it may be a consequence of the different synthesis routes employed. The previously reported structural data for $\mathrm{Nd}_{0.5} \mathrm{Ca}_{0.5^{-}}$ $\mathrm{MnO}_{3}$ and $\mathrm{Pr}_{0.5} \mathrm{Ca}_{0.5} \mathrm{MnO}_{3}$ were obtained from analysis of conventional X-ray and low-resolution neutron powder diffraction data, respectively. The bond distances and angles determined in these studies were not of sufficient accuracy to be used in this study, although they are in relatively good agreement with our results.

The structure of $\mathrm{La}_{0.5} \mathrm{Sr}_{0.5} \mathrm{MnO}_{3}$ has also been re ported in the literature, to be monodinic, space group 12/a (tilt system $a^{-} b^{-} a^{-}$), based on refinements of conventional X-ray diffraction data. ${ }^{33}$ However, we observe a two-phase orthorhombic (I mma) and tetragonal $(14 / \mathrm{mcm})$ mixture. The distinction between I mma and I $2 / a$ is a subtle one. Both space groups have the same extinction conditions. Therefore, the two can only be distinguished by the presence of a monoclinic distortion; and/or small changes in the peak intensities. For each compound we assigned to the I mma space group, we also performed refinements in the 12/a space group. In each case, neither the profile fit nor the goodness of fit residuals showed any improvement over the fit obtained using the I mma model. Thus, we reached the conclusion that all of the compounds reported here as I mma are orthorhombic rather than monoclinic. It is not clear if the discrepancy between our results and the previously reported structure of $\mathrm{La}_{0.5} \mathrm{Sr}_{0.5} \mathrm{MnO}_{3}$ is due to differences in the synthesis route, problems in correctly interpreting the lower resolution laboratory X-ray diffraction data used in the previous study (particularly if the sample was actually two-phase), or masking of a slight monoclinic distortion in our sample due to the coexistence of two phases.

\section{Discussion}

Bond Distances, Angles, and Unit Cell Parameters. In analyzing the data we first examined the validity of the assumptions made. Figure 3 shows the evolution of $\langle\omega\rangle$, defined as

$$
\langle\omega\rangle=180^{\circ}-\langle\alpha\rangle
$$

where $\langle\alpha\rangle$ is the average value of the $\mathrm{Mn}-\mathrm{O}-\mathrm{Mn}$ angles. Taken on the whole, $\langle\omega\rangle$ increases roughly proportionally to the decrease in $\left\langle r_{A}\right\rangle$, although the linear fit to the $\langle\omega\rangle$ values for the strontium-containing compounds is not particularly good. Examination of the average $\mathrm{Mn}-\mathrm{O}$ bond distances in Tables 8 and 9 shows that this 
Table 4. Refinement Statistics, Unit Cell Dimensions, and Microstrain Parameters for $\mathrm{Ln}_{0.5} \mathrm{Ca}_{5} \mathrm{MnO}_{3} \mathrm{Compounds}$

\begin{tabular}{|c|c|c|c|c|c|c|}
\hline Ianthanide & La & $\mathrm{La}_{0.5} \mathrm{Nd}_{0.5}$ & $\mathrm{Pr}$ & $\mathrm{Nd}$ & $\mathrm{Sm}$ & $\mathrm{Sm}_{0.5} \mathrm{Y}_{0.5}$ \\
\hline $\mathrm{R}_{\mathrm{wp}}$ & $4.10 \%$ & $5.03 \%$ & $3.85 \%$ & $4.90 \%$ & $6.20 \%$ & $7.22 \%$ \\
\hline $\mathrm{R}_{\mathrm{P}}$ & $2.93 \%$ & $3.24 \%$ & $2.61 \%$ & $3.35 \%$ & $3.41 \%$ & $4.84 \%$ \\
\hline $\mathrm{R}\left(\mathrm{F}^{2}\right)$ & $4.93 \%$ & $4.12 \%$ & $3.82 \%$ & $4.47 \%$ & $5.98 \%$ & $6.01 \%$ \\
\hline $2 \theta$ range & $10-80^{\circ}$ & $9-71^{\circ}$ & $9-72^{\circ}$ & $10-60^{\circ}$ & $10-79^{\circ}$ & $9-62^{\circ}$ \\
\hline \# reflections & 554 & 449 & 429 & 258 & 549 & 295 \\
\hline \#variables & 19 & 19 & 19 & 19 & 19 & 19 \\
\hline space group & Pnma & Pnma & Pnma & Pnma & Pnma & Pnma \\
\hline a $(\AA)$ & $5.41822(4)$ & $5.4077(2)$ & $5.40428(5)$ & $5.39200(6)$ & $5.41593(5)$ & $5.4254(3)$ \\
\hline $\mathrm{b}(\AA)$ & $7.63890(4)$ & $7.6246(1)$ & $7.61275(5)$ & 7.58972(8) & 7.54849(7) & $7.5042(3)$ \\
\hline$c(\AA)$ & $5.42691(4)$ & $5.4047(2)$ & $5.39414(4)$ & $5.37605(6)$ & $5.36012(6)$ & $5.3341(2)$ \\
\hline volume $\left(\AA^{3}\right)$ & $224.616(3)$ & $222.840(5)$ & $221.923(3)$ & $220.008(5)$ & 219.133(5) & $217.17(2)$ \\
\hline strain ${ }^{74}$ (Gauss) & $0.104 \%$ & $0.161 \%$ & $0.117 \%$ & $0.123 \%$ & $0.254 \%$ & $0.327 \%$ \\
\hline strain $^{74}$ (Lorentz) & $0.051 \%$ & $0.131 \%$ & $0.047 \%$ & $0.068 \%$ & $0.087 \%$ & 0 \\
\hline
\end{tabular}

Table 5. Refined Fractional Coordinates and Displacement Parameters for Tetragonal $\mathrm{Ln}_{0.5} \mathrm{Sr}_{0.5} \mathrm{MnO}_{3}$ Compounds

\begin{tabular}{ccc}
\hline Ianthanide & La & $\mathrm{Pr}$ \\
\hline $\mathrm{O}_{\mathrm{EQ}} \mathrm{X}$ & fractional coordinates & \\
$\mathrm{O}_{\mathrm{EQ}} \mathrm{y}$ & $0.7751(7)$ & $0.7845(4)$ \\
& $0.2751(7)$ & $0.2845(4)$ \\
$\mathrm{Ln} / \mathrm{Sr}$ & displacement parameter, $\mathrm{B}_{\text {ISO }}\left(\AA^{2}\right)$ \\
$\mathrm{Mn}$ & $0.273(6)$ & $0.197(7)$ \\
$\mathrm{O}_{\mathrm{AX}}$ & $0.11(1)$ & $-0.03(1)$ \\
$\mathrm{O}_{\mathrm{EQ}}$ & $0.32(5)^{\mathrm{b}}$ & $0.53(7)$ \\
& $0.32(5)^{\mathrm{b}}$ & $0.30(6)$
\end{tabular}

a These compounds possess $14 / \mathrm{mcm}$ symmetry, with the $\mathrm{Ln} / \mathrm{Sr}$ ions residing on the $4 \mathrm{~b}$ site $(0,1 / 2,1 / 4), \mathrm{Mn}$ on $4 \mathrm{c}$ site $(0,0,0), \mathrm{O}_{A X}$ on $4 a$ site $(0,0,1 / 4)$, and $\mathrm{O}_{\mathrm{EQ}}$ on $8 \mathrm{~h}$ site $(x, x+1 / 2,0)$. ${ }^{\mathrm{b}}$ Oxygen displacement parameters were constrained to be equal for $\mathrm{La}_{0.5} \mathrm{Sr}_{0.5} \mathrm{MnO}_{3}$.

distance is more or less constant across the entire series, the observed spread in values being 1.935-1.947 $\AA$. There does appear to be a slight increase in $\left\langle\mathrm{d}_{\mathrm{Mn}-0}\right\rangle$ with decreasing $\left\langle r_{A}\right\rangle$, but the uncertainties in the $\mathrm{Mn}-\mathrm{O}$ distances render any proposed correlation between these two parameters statistically insignificant. Furthermore, the observed variation in the manganese bond valence, $3.59-3.72$, is quite small, ${ }^{46}$ suggesting that the total $\mathrm{Mn}-\mathrm{O}$ bonding interaction is practically constant across the series.

At first glance it would seem that the practice of correlating changes in the $\mathrm{Mn}-\mathrm{O}-\mathrm{Mn}$ bond angles directly with $\left\langle r_{A}\right\rangle$ is valid. However, a closer look at the data reveals the oversimplification of such an assumption. Figure 4 shows the behavior of the individual $\mathrm{Mn}-\mathrm{O}$ distances and $\mathrm{Mn}-\mathrm{O}-\mathrm{Mn}$ angles versuss the Goldschmidt tolerance factor: 47

$$
t=\left(r_{A}+r_{O}\right) /\left[\sqrt{2}\left(r_{M}+r_{O}\right)\right]
$$

where $r_{A}, r_{M}$, and $r_{O}$ are the ionic radii of the constituent ions. Examining first the $\mathrm{Mn}-\mathrm{O}$ distances, we see that for large and particularly for small values of $\left\langle r_{A}\right\rangle$ (or tolerance factor), the $\mathrm{Mn}-\mathrm{O}(\mathrm{ax})$ distances are shorter than the $\mathrm{Mn}-\mathrm{O}(\mathrm{eq})$ distances. ${ }^{48}$ Because the e electrons are $\sigma$-antibonding, any localization or confinement of them to a specific plane or direction will result in an expansion of the bonds in that direction(s). Therefore, the divergence of the $\mathrm{Mn}-\mathrm{O}(\mathrm{ax})$ and $\mathrm{Mn}-\mathrm{O}(\mathrm{eq})$ values

(46) For comparison, the manganese bond valence in $\mathrm{Nd}_{0.5} \mathrm{Ca}_{0.5}$ $\mathrm{MnO}_{3}$ was calculated using $\mathrm{Mn}-\mathrm{O}$ distances that were first expanded and then contracted by experimentally determined standard deviation. The resulting manganese bond valences were 3.71 and 3.62, comparable to the deviation observed across the entire $L n_{0.5} A_{0.5} M_{n O}$ series.

(47) Goldschmidt, V. M. Naturwissenschaften 1926, 14, 477.

for compounds with $\mathrm{A}=\mathrm{Ca}$ as the ionic radius of the lanthanide ion decreases reflects an increase in the degree of orbital ordering present at room temperature. This increase is presumably driven by an increased localization of the carriers as the $\sigma^{*}$ bandwidth, W, decreases in response to the increased distortion of the $\mathrm{Mn}-\mathrm{O}-\mathrm{Mn}$ bonds, $\langle\omega\rangle$.

The observation that $\mathrm{Mn}-\mathrm{O}(\mathrm{ax})$ distances are smaller in the large tolerance factor region is not so easily understood. Because $\langle\omega\rangle$ is smaller, W is larger and higher carrier mobility is expected. Delocalization of the $e_{g}$ electrons should lead to a very isotropic distribution of $\mathrm{Mn}-\mathrm{O}$ distances. The explanation to this apparent anomaly is contained in Figure $4 \mathrm{~b}$. With the exception of $\mathrm{La}_{0.5} \mathrm{Ca}_{0.5} \mathrm{MnO}_{3}$, theassumption of isotropic $\mathrm{Mn}-\mathrm{O}-\mathrm{Mn}$ bond angles is a very good one for the $\mathrm{Ln}_{0.5} \mathrm{Ca}_{0.5} \mathrm{MnO}_{3}$ series, but does not hold for the $\mathrm{Ln}_{0.5} \mathrm{Sr}_{0.5} \mathrm{MnO}_{3}$ series. The $\mathrm{Mn}-\mathrm{O}(\mathrm{eq})-\mathrm{Mn}$ angles are consistently larger than their $\mathrm{Mn}-\mathrm{O}(\mathrm{ax})-\mathrm{Mn}$ counterparts, in some cases by $>5^{\circ}$. As a result, the $\sigma^{*}$ bandwidth in the $\mathrm{MnO}(\mathrm{eq})_{2}$ layers will be larger than the bandwidth in the $\mathrm{Mn}-\mathrm{O}(\mathrm{ax})$ direction, which will increase in-plane carrier mobility and magnetic superexchange interactions. Thus, to promote delocalization of the carriers and reap a subsequent gain in kinetic energy, the $e_{g}$ orbitals with significant components in the $\mathrm{MnO}\left(\right.$ eq) ${ }_{2}$ layers will be preferentially populated over the $e_{g}$ orbitals directed primarily along the $\mathrm{Mn}-$ $\mathrm{O}(\mathrm{ax})$ directions. This procedure will result in an expansion of the $\mathrm{Mn}-\mathrm{O}$ (eq) bonds, with respect to the $\mathrm{Mn}-\mathrm{O}(\mathrm{ax})$ bonds.

Finally, the $\mathrm{M}-\mathrm{O}-\mathrm{M}$ angles are shown for $\mathrm{LnMO}_{3}$ $(\mathrm{M}=\mathrm{Fe}, \mathrm{Al})$ compounds in Figure $4 \mathrm{c}$ for comparison. Among these compounds, notice that even over a wide range of tolerance factor, no significant deviation of the $\mathrm{M}-\mathrm{O}(\mathrm{eq})-\mathrm{M}$ and $\mathrm{M}-\mathrm{O}(\mathrm{ax})-\mathrm{M}$ values is observed. This implies indirectly that the anisotropy in the $\mathrm{Ln}_{0.5} \mathrm{~A}_{0.5^{-}}$ $\mathrm{MnO}_{3}$ series is a consequence of the size mismatch between $\mathrm{Sr}^{2+}$ and $\mathrm{Ln}^{3+}$. This point will be discussed in greater detail in the discussion of octahedral tilting, as

(48) The $\mathrm{O}(\mathrm{eq})$ atoms are defined as those atoms that lie roughly in the plane in which the occupied eg orbitals order. These $\mathrm{MnO}(\mathrm{eq})_{2}$ layers also correspond to the ferromagnetic layers in the AFM-A type structure. In the Pnma and I mma space groups, the $\mathrm{MnO}(\mathrm{eq})_{2}$ layers run parallel to the ac plane; in $14 / \mathrm{mcm}$, the layers are defined in the bc plane. The $\mathrm{O}(\mathrm{ax})$ atoms link the $\mathrm{MnO}(\mathrm{eq})_{2}$ layers. This definition of making the "unique" axis along b is consistent with the tilt system for Pnma and Imma compounds, but calling a "unique" is contrary to convention for the tetragonal space group $14 / \mathrm{mcm}$. However, such a definition is consistent with the magnetic and orbital ordering observed for $\mathrm{Pr}_{0.5} \mathrm{Sr}_{0.5} \mathrm{MnO}_{3},{ }^{47}$ as well as the convention of having the most distorted $\mathrm{Mn}-\mathrm{O}-\mathrm{Mn}$ linkages run in the axial direction. 
Table 6. Refined Fractional Coordinates and Displacement Parameters for Orthorhombic $\mathrm{Ln}_{0.5} \mathrm{Sr}_{0.5} \mathrm{MnO}_{3} \mathrm{Compounds}_{0}$

\begin{tabular}{|c|c|c|c|c|c|}
\hline lanthanide & $\mathrm{La}_{0.33} \mathrm{Nd}_{0.67^{\mathrm{a}}}$ & $\mathrm{Nd} d^{\mathrm{a}}$ & $\mathrm{Nd}_{0.5} \mathrm{Sm}_{0.5}{ }^{\mathrm{a}}$ & $\mathrm{Sm}^{\mathrm{b}}$ & $\mathrm{Gd}^{\mathrm{b}}$ \\
\hline \multicolumn{6}{|c|}{ fractional coordinate } \\
\hline $\operatorname{Ln} / \mathrm{Sr} x$ & 0 & 0 & 0 & $0.0158(1)$ & $0.0235(1)$ \\
\hline $\mathrm{Ln} / \mathrm{Sr} \mathrm{z}$ & $-0.0012(4)$ & $-0.0019(3)$ & $-0.0020(2)$ & $-0.0027(3)$ & $-0.0051(3)$ \\
\hline $\mathrm{O}_{\mathrm{AX}} \mathrm{x}$ & 0 & 0 & 0 & $-0.000(1)$ & $-0.006(1)$ \\
\hline $\mathrm{O}_{A X \mathrm{Z}}$ & $0.448(1)$ & $0.4462(9)$ & $0.4437(7)$ & $0.440(1)$ & $0.435(2)$ \\
\hline $\mathrm{O}_{E Q} \mathrm{X}$ & 0.75 & 0.75 & 0.75 & $0.731(2)$ & $0.726(1)$ \\
\hline $\mathrm{O}_{\mathrm{EOO} Y} \mathrm{Y}$ & $-0.0250(7)$ & $-0.0269(5)$ & $-0.0284(5)$ & $-0.0295(6)$ & $-0.0322(7)$ \\
\hline $\mathrm{O}_{\mathrm{EQ}} \mathrm{Z}$ & 0.25 & 0.25 & 0.25 & $0.269(2)$ & $0.275(1)$ \\
\hline \multicolumn{6}{|c|}{ displacement parameter, $\mathrm{B}_{\mathrm{ISO}}\left(\AA^{2}\right)$} \\
\hline $\mathrm{Ln} / \mathrm{Sr}$ & $0.276(9)$ & $0.317(7)$ & $0.497(6)$ & $0.30(1)$ & $0.276(9)$ \\
\hline $\mathrm{Mn}$ & $0.06(1)$ & $0.12(1)$ & $0.19(1)$ & $-0.02(2)$ & $0.02(1)$ \\
\hline $\mathrm{O}_{A x}$ & $0.5(2)$ & $0.6(1)$ & $0.53(8)$ & $\begin{array}{l}0.9(2) \\
\text { la }\end{array}$ & $1.6(3)$ \\
\hline $\mathrm{O}_{\mathrm{EO}}$ & $0.29(8)$ & $0.60(7)$ & $1.02(6)$ & $0.3(1)$ & $0.1(1)$ \\
\hline
\end{tabular}

a These compounds possess I mma symmetry, with the $\mathrm{Ln} / \mathrm{Sr}$ and $\mathrm{O}_{A X}$ ions residing on the 4 e site $(0,1 / 4, \mathrm{z}), \mathrm{Mn}$ on $4 \mathrm{~b}$ site $(0,0,1 / 2)$, and $\mathrm{O}_{\mathrm{EQ}}$ on $8 \mathrm{~g}$ site $(3 / 4, \mathrm{y}, 1 / 4)$. ${ }^{\mathrm{b}}$ These compounds possess Pnma symmetry, with the $\mathrm{Ln} / \mathrm{Sr}$ and $\mathrm{O}_{\mathrm{AX}}$ ions residing on the $4 \mathrm{C}$ site $(\mathrm{x}, 1 / 4, \mathrm{z})$, $\mathrm{Mn}$ on $4 b$ site $(0,0,1 / 2)$, and $O_{E Q}$ on $8 d$ site $(x, y, z)$.

Table 7. Refined Fractional Coordinates and Displacement Parameters for $\mathrm{Ln}_{0.5} \mathrm{Ca}_{0.5} \mathrm{MnO}_{3} \mathrm{Compounds}$

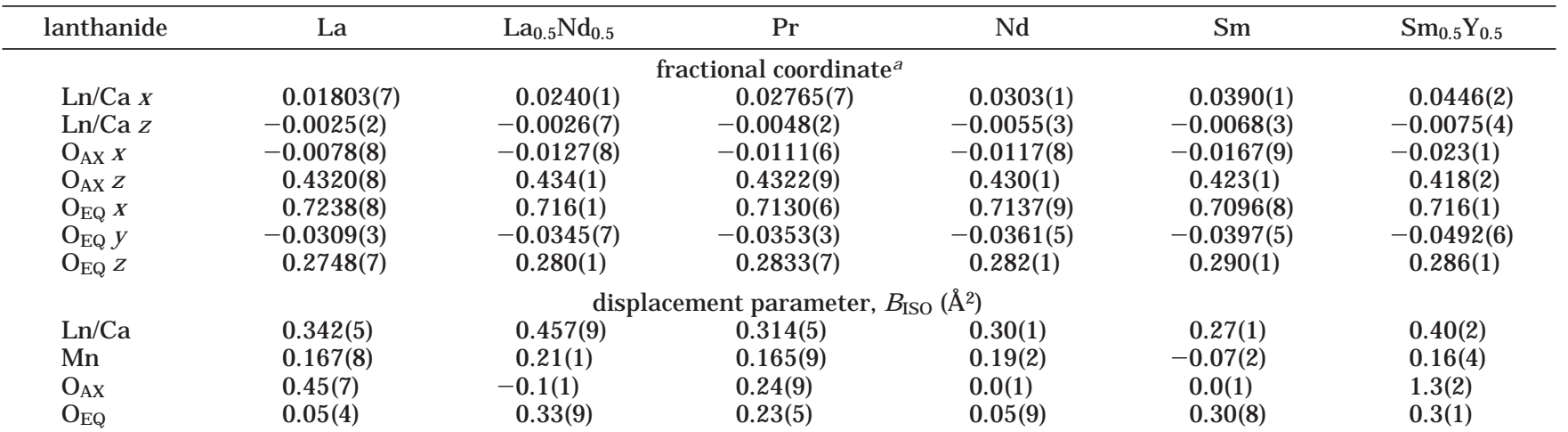

a All compounds possess Pnma symmetry, with the $L n / C a$ and $O_{A X}$ ions residing on the $4 c$ site $(x, 1 / 4, z), M n$ on $4 b$ site $(0,0,1 / 2)$, and $O_{E Q}$ on $8 d$ site $(x, y, z)$.

Table 8. Key Structural Features for $\mathrm{Ln}_{0.5} \mathrm{Sr}_{0.5} \mathrm{MnO}_{3}$ Compounds

\begin{tabular}{|c|c|c|c|c|c|c|c|}
\hline Lanthanide & La & $\mathrm{Pr}$ & $\mathrm{La}_{0.33} \mathrm{Nd}_{0.67}$ & $\mathrm{Nd}$ & $\mathrm{Nd}_{0.5} \mathrm{Sm}_{0.5}$ & Sm & $\mathrm{Gd}$ \\
\hline \multicolumn{8}{|c|}{ structural feature } \\
\hline$\left\langle r_{A}\right\rangle^{a}$ & 1.263 & 1.245 & 1.250 & 1.237 & 1.229 & 1.221 & 1.209 \\
\hline$r_{A}-r_{L n}$ & 0.094 & 0.131 & 0.121 & 0.147 & 0.163 & 0.178 & 0.203 \\
\hline$t_{9}$ & 0.953 & 0.947 & 0.949 & 0.944 & 0.941 & 0.938 & 0.934 \\
\hline & 1.004 & 0.994 & 0.995 & 0.987 & 0.984 & 0.982 & 0.976 \\
\hline tilt system & $a^{0} a^{0} c^{-}$ & $a^{0} a^{0} c^{-}$ & $a^{-} b^{0} a^{-}$ & $a^{-} b^{0} a^{-}$ & $a^{-} b^{0} a^{-}$ & $a^{-} b^{+} a^{-}$ & $a^{-} b^{+} a^{-}$ \\
\hline \multicolumn{8}{|c|}{ bond distance $(\AA)$} \\
\hline $\mathrm{Mn}-\mathrm{O}_{\mathrm{Ax}}$ & $2 \times 1.9338(5)$ & $2 \times 1.9283(4)$ & $2 \times 1.933(1)$ & $2 \times 1.9310(7)$ & $2 \times 1.9309(7)$ & $2 \times 1.937(1)$ & $2 \times 1.943(2)$ \\
\hline $\mathrm{Mn}-\mathrm{O}_{\mathrm{EQ}}$ & $\begin{array}{l}2 \times 1.9338(5) \\
2 \times 1\end{array}$ & $\begin{array}{l}2 \times 1.9283(4) \\
2 \times 1.9469(1)\end{array}$ & $4 \times 1.9389(5)$ & $4 \times 1.9391(4)$ & $4 \times 1.9367(4)$ & $\begin{array}{l}2 \times 1.94(1) \\
2 \times 1.94(1)\end{array}$ & $\begin{array}{l}2 \times 1.938(4) \\
2 \times 1.946(4)\end{array}$ \\
\hline$\langle d\rangle$ & $1.9364(4)$ & $1.9345(3)$ & $1.9369(7)$ & $1.9364(4)$ & $1.9347(4)$ & $1.939(7)$ & $1.942(3)$ \\
\hline \multicolumn{8}{|l|}{ bond angle $\left({ }^{\circ}\right)$} \\
\hline$M n-O_{A x}-M n$ & 168.6(3) & 164.3(2) & $162.9(4)$ & $162.4(3)$ & $161.7(2)$ & $160.7(4)$ & 159.1(7) \\
\hline $\mathrm{Mn}-\mathrm{O}_{\mathrm{EQ}}-\mathrm{Mn}$ & $\begin{array}{l}168.6(3) \\
180.0\end{array}$ & $\begin{array}{l}164.3(2) \\
180.0\end{array}$ & 168.7(3) & $167.8(2)$ & $167.2(2)$ & 164.1(3) & 161.6(3) \\
\hline$\langle\omega\rangle$ & $7.6(2)$ & $10.5(1)$ & 13.2(3) & $14.0(2)$ & 14.6(2) & $17.0(3)$ & 19.2(4) \\
\hline $\mathrm{O}_{\mathrm{AX}}-\mathrm{Mn}-\mathrm{O}_{\mathrm{EQ}}$ & 90.0 & 90.0 & $89.6(2)$ & $89.8(2)$ & 89.9(1) & $\begin{array}{l}89.7(3) \\
89.3(3)\end{array}$ & $\begin{array}{l}90.0(4) \\
89.8(4)\end{array}$ \\
\hline \multirow[t]{2}{*}{$\mathrm{O}_{E Q}-\mathrm{Mn}-\mathrm{O}_{\mathrm{EQ}}$} & 90.0 & 90.0 & $89.05(3)$ & $88.89(2)$ & $88.87(2)$ & $88.93(5)$ & $89.10(5)$ \\
\hline & & & bandwic & & & & \\
\hline $\cos \left\langle\omega_{A X}\right\rangle$ & 0.9802 & 0.9626 & 0.9558 & 0.9532 & 0.9494 & 0.9438 & 0.9342 \\
\hline $\cos \left\langle\omega_{\mathrm{EO}}\right\rangle$ & 0.9950 & 0.9906 & 0.9806 & 0.9774 & 0.9751 & 0.9617 & 0.9489 \\
\hline$\left(\cos \omega_{A X}\right) /\left(\cos \omega_{E Q}\right)$ & $98.5 \%$ & $97.2 \%$ & $97.5 \%$ & $97.5 \%$ & $97.4 \%$ & $98.1 \%$ & $98.5 \%$ \\
\hline \multicolumn{8}{|c|}{ bond valences ${ }^{\mathrm{b}}$} \\
\hline $\mathrm{Sr}$ & 2.39 & 2.53 & 2.55 & 2.59 & 2.64 & 2.73 & 2.85 \\
\hline Ln & 2.76 & 2.67 & $\begin{array}{l}2.95(\mathrm{La}) \\
2.46(\mathrm{Nd})\end{array}$ & 2.50 & $\begin{array}{l}2.55(\mathrm{Nd}) \\
2.45(\mathrm{Sm})\end{array}$ & 2.53 & 2.52 \\
\hline$(\mathrm{Ln}+\mathrm{Sr}) / 2$ & 2.58 & 2.60 & 2.63 & 2.55 & 2.57 & 2.63 & 2.69 \\
\hline $\mathrm{Mn}$ & 3.70 & 3.72 & 3.69 & 3.70 & 3.71 & 3.67 & 3.64 \\
\hline
\end{tabular}

a Calculated from Shannon's nine-coordinate ionic radii. ${ }^{75}$ b The bond val ence calculations were performed with the program Valence. ${ }^{76}$

will the fact that the bond angle anisotropy is most strongly associated with the I $\mathrm{mma}$ and $14 / \mathrm{mcm}$ space groups.
The evolution of the lattice parameters and unit cell volume as a function of $\left\langle r_{A}\right\rangle$ is shown in Figure 5 . The corresponding values for the $\mathrm{LnFeO}_{3}$ and $\mathrm{LnAlO}_{3}$ series 
Table 9. Key Structural Features for $\mathrm{Ln}_{0.5} \mathrm{Ca}_{0.5} \mathrm{MnO}_{3}$ Compounds

\begin{tabular}{|c|c|c|c|c|c|c|}
\hline lanthanide & $\mathrm{La}$ & $\mathrm{La}_{0.5} \mathrm{Nd}_{0.5}$ & $\mathrm{Pr}$ & $\mathrm{Nd}$ & $\mathrm{Sm}$ & $\mathrm{Sm}_{0.5} \mathrm{Y}_{0.5}$ \\
\hline $\begin{array}{l}\left\langle r_{A}\right\rangle^{a} \\
r_{A}-r_{L n} \\
t_{9} \\
t_{12} \\
\text { tilt system }\end{array}$ & $\begin{array}{l}1.198 \\
-0.036 \\
0.930 \\
0.985 \\
a^{-} b^{+} a^{-}\end{array}$ & $\begin{array}{l}1.185 \\
-0.010 \\
0.925 \\
0.977 \\
a^{-} b^{+} a^{-}\end{array}$ & $\begin{array}{l}\text { ctural feature } \\
1.180 \\
0.001 \\
0.923 \\
0.975 \\
a^{-} b^{+} a^{-}\end{array}$ & $\begin{array}{l}1.172 \\
0.017 \\
0.920 \\
0.969 \\
a^{-} b^{+} a^{-}\end{array}$ & $\begin{array}{l}1.156 \\
0.048 \\
0.915 \\
0.963 \\
a^{-} b^{+} a^{-}\end{array}$ & $\begin{array}{l}1.142 \\
0.077 \\
0.909 \\
0.956 \\
a^{-} b^{+} a^{-}\end{array}$ \\
\hline $\begin{array}{l}\mathrm{Mn}-\mathrm{O}_{\mathrm{AX}} \\
\mathrm{Mn}-\mathrm{O}_{\mathrm{EQ}} \\
\langle\mathrm{d}\rangle\end{array}$ & $\begin{array}{l}2 \times 1.946(1) \\
2 \times 1.946(5) \\
2 \times 1.937(5) \\
1.943(4)\end{array}$ & $\begin{array}{l}2 \times 1.940(1) \\
2 \times 1.961(8) \\
2 \times 1.928(8) \\
1.943(6)\end{array}$ & $\begin{array}{l}\text { distance }(\AA) \\
2 \times 1.939(1) \\
2 \times 1.961(4) \\
2 \times 1.932(4) \\
1.944(3)\end{array}$ & $\begin{array}{l}2 \times 1.936(2) \\
2 \times 1.957(6) \\
2 \times 1.925(6) \\
1.939(5)\end{array}$ & $\begin{array}{l}2 \times 1.933(1) \\
2 \times 1.956(5) \\
2 \times 1.949(5) \\
1.946(4)\end{array}$ & $\begin{array}{l}2 \times 1.931(2) \\
2 \times 1.952(8) \\
2 \times 1.960(8) \\
1.947(6)\end{array}$ \\
\hline $\begin{array}{l}M n-O_{A X}-M n \\
M n-O_{E Q}-M n \\
\langle\omega\rangle \\
O_{A X}-M n-O_{E Q} \\
O_{E Q}-M n-O_{E Q}\end{array}$ & $\begin{array}{l}158.0(3) \\
161.8(1) \\
160.5(2) \\
89.0(2) \\
89.3(1) \\
89.03(3)\end{array}$ & $\begin{array}{l}158.5(4) \\
158.8(3) \\
158.7(3) \\
89.6(3) \\
89.3(3) \\
88.86(8)\end{array}$ & $\begin{array}{l}\text { nd angle }\left({ }^{\circ}\right) \\
158.0(3) \\
157.5(2) \\
157.7(2) \\
89.9(2) \\
89.7(3) \\
88.89(4)\end{array}$ & $\begin{array}{l}157.2(4) \\
157.5(2) \\
157.4(3) \\
89.7(2) \\
89.7(3) \\
88.90(6)\end{array}$ & $\begin{array}{l}154.9(4) \\
154.6(2) \\
154.7(3) \\
89.4(2) \\
89.6(2) \\
89.20(6)\end{array}$ & $\begin{array}{l}152.7(6) \\
153.1(4) \\
153.0(5) \\
87.5(3) \\
90.0(3) \\
88.93(9)\end{array}$ \\
\hline $\begin{array}{l}\cos \left\langle\omega_{\mathrm{AX}}\right\rangle \\
\cos \left\langle\omega_{\mathrm{EQ}}\right\rangle \\
\left(\cos \omega_{\mathrm{AX}}\right) /\left(\cos \omega_{\mathrm{EQ}}\right)\end{array}$ & $\begin{array}{l}0.9272 \\
0.9499 \\
97.6 \%\end{array}$ & $\begin{array}{l}0.9304 \\
0.9323 \\
99.8 \%\end{array}$ & $\begin{array}{l}\text { andwidth } \\
0.9272 \\
0.9239 \\
100.4 \%\end{array}$ & $\begin{array}{l}0.9218 \\
0.9239 \\
99.8 \%\end{array}$ & $\begin{array}{l}0.9056 \\
0.9033 \\
100.3 \%\end{array}$ & $\begin{array}{l}0.8887 \\
0.8918 \\
99.6 \%\end{array}$ \\
\hline $\begin{array}{l}\mathrm{Ca} \\
\mathrm{Ln}\end{array}$ & $\begin{array}{l}1.81 \\
3.32\end{array}$ & $\begin{array}{l}1.91 \\
3.33(\mathrm{La}) \\
2.84(\mathrm{Nd})\end{array}$ & $\begin{array}{l}\text { nd valence } \\
1.98 \\
3.14\end{array}$ & $\begin{array}{l}2.03 \\
2.94\end{array}$ & $\begin{array}{l}2.17 \\
3.10\end{array}$ & $\begin{array}{l}2.31 \\
3.30(\mathrm{Sm}) \\
2.74(\mathrm{Y})\end{array}$ \\
\hline $\begin{array}{l}(\mathrm{Ln}+\mathrm{Ca}) / 2 \\
\mathrm{Mn}\end{array}$ & $\begin{array}{l}2.57 \\
3.63\end{array}$ & $\begin{array}{l}2.50 \\
3.63\end{array}$ & $\begin{array}{l}2.56 \\
3.62\end{array}$ & $\begin{array}{l}2.49 \\
3.67\end{array}$ & $\begin{array}{l}2.64 \\
3.60\end{array}$ & $\begin{array}{l}2.67 \\
3.59\end{array}$ \\
\hline
\end{tabular}

a Calculated from Shannon's nine-coordinate ionic radii. ${ }^{75}$ b The bond valence calculations were performed with the program Valence. ${ }^{76}$

Table 10. Iodometric Titration Results

\begin{tabular}{lcc}
\hline \multicolumn{1}{c}{ compound } & $x^{\mathrm{a}}$ & $\begin{array}{c}\text { manganese } \\
\text { oxidation state }\end{array}$ \\
\hline $\mathrm{La}_{0.5} \mathrm{Sr}_{0.5} \mathrm{MnO}_{3-x}$ & $0.001(1)$ & 3.50 \\
$\mathrm{La}_{0.17} \mathrm{Nd}_{0.33} \mathrm{Sr}_{0.5} \mathrm{MnO}_{3-x}$ & $0.001(1)$ & 3.50 \\
$\mathrm{Pr}_{0.5} \mathrm{Sr}_{0.5} \mathrm{MnO}_{3-x}$ & $0.000(1)$ & 3.50 \\
$\mathrm{Nd}_{0.5} \mathrm{Sr}_{0.5} \mathrm{MnO}_{3-x}$ & $0.003(1)$ & 3.49 \\
$\mathrm{Nd}_{0.25} \mathrm{Sm}_{0.25} \mathrm{Sr}_{0.5} \mathrm{MnO}_{3-x}$ & $-0.004(2)$ & 3.51 \\
$\mathrm{Sm}_{0.5} \mathrm{Sr}_{0.5} \mathrm{MnO}_{3-x}$ & $-0.007(4)$ & 3.51 \\
$\mathrm{Gd}_{0.5} \mathrm{Sr}_{0.5} \mathrm{MnO}_{3-x}$ & $0.002(2)$ & 3.50 \\
$\mathrm{La}_{0.5} \mathrm{Ca}_{0.5} \mathrm{MnO}_{3-x}$ & $0.005(2)$ & 3.49 \\
$\mathrm{La}_{0.25} \mathrm{Nd}_{0.25} \mathrm{Ca}_{0.5} \mathrm{MnO}_{3-x}$ & $0.005(6)$ & 3.49 \\
$\mathrm{Pr}_{0.5} \mathrm{Ca}_{0.5} \mathrm{MnO}_{3-x}$ & $0.003(1)$ & 3.49 \\
$\mathrm{Nd}_{0.5} \mathrm{Ca}_{0.5} \mathrm{MnO}_{3-x}$ & $-0.013(2)$ & 3.53 \\
$\mathrm{Sm}_{0.5} \mathrm{Ca}_{0.5} \mathrm{MnO}_{3-x}$ & $-0.012(3)$ & 3.52 \\
$\mathrm{Sm}_{0.25} \mathrm{Y}_{0.25} \mathrm{Ca}_{0.5} \mathrm{MnO}_{3-x}$ & $-0.009(3)$ & 3.52
\end{tabular}

a Three to four runs were performed on each sample. The standard deviations are based strictly on the statistical repeatability, the real standard error of each analysis is probably at least twice the statistical standard deviation.

are contained in Figure 6 . Based on the $\mathrm{GdFeO}_{3}$ octahedral tilting distortion al one (tilt system $a^{-} b^{+} a^{-}$), the so-called O-type lattice distortion $a \geq b / \sqrt{2} \geq \mathrm{c}$ is expected. This relationship holds for the entire $\mathrm{LnFeO}_{3}$ series, which is consistent with the fact that octahedral tilting is essentially the only distortion mechanism present in that series. ${ }^{49}$ Figure 6 al so shows that the $c$ lattice parameter is most sensitive to the octahedral tilting distortion, while the a parameter is relatively insensitive to such a distortion. It is also known that the combination of octahedral tilting and a cooperative JT distortion (orbital ordering) produces the O'-type lattice distortion, with $\mathrm{a} \geq \mathrm{c} \geq \mathrm{b} / \sqrt{2}$. $^{45,50}$ High-temperature X-ray studies of $\mathrm{Pr}_{1-x} \mathrm{Ca}_{x} \mathrm{MnO}_{3}$ and

(49) Marezio, M.; Remeika, J . P.; Dernier, P. D. Acta Crystallogr. B 1970, 26, 2008.

(50) Pollert, E.; Krupicka, S.; Kuzmicova, E. J . Phys. Chem. Solids 1982, 43, 1137.

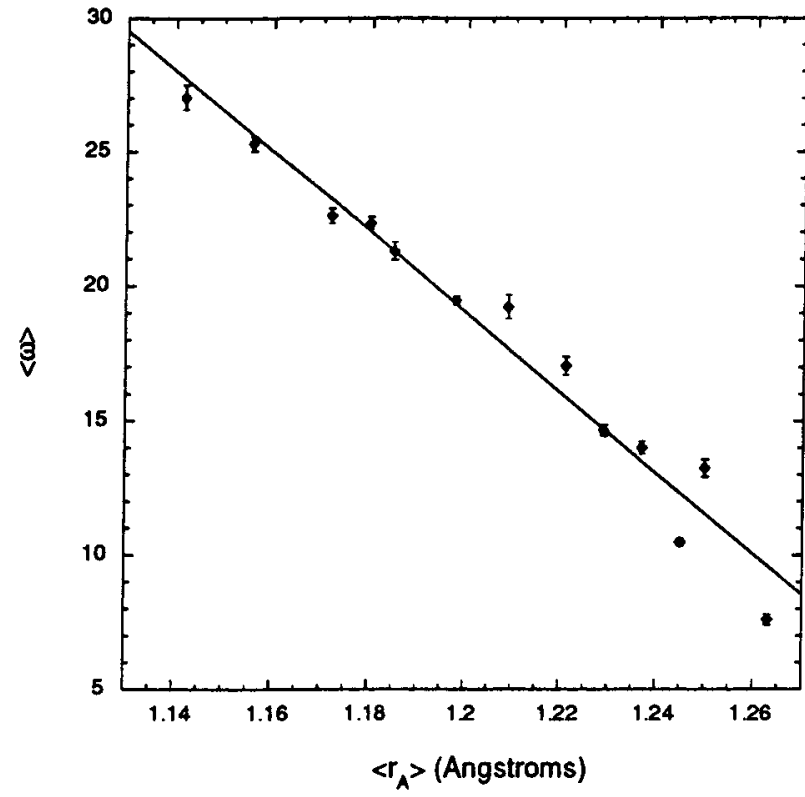

Figure 3. The average $\mathrm{Mn}-\mathrm{O}-\mathrm{Mn}$ angle distortion, $\langle\mathrm{w}\rangle=$ $180-\langle\alpha\rangle$, where $\langle\alpha\rangle$ is the average $\mathrm{Mn}-\mathrm{O}-\mathrm{Mn}$ bond angle as a function of $\left\langle r_{A}\right\rangle$.

$\mathrm{Y}_{1-x} \mathrm{Ca}_{x} \mathrm{MnO}_{3}$ show that the development of orbital ordering results primarily in a large expansion in thea cell parameter, and a smaller contraction in $\mathrm{b} / \sqrt{2}$ (Pnma setting). ${ }^{50}$ Thus, changes in the c cell parameter are reflective of the magnitude of the octahedral tilting distortion, whereas changes in the a cell parameter serve as a good indicator of the magnitude of the cooperative J T distortion.

Using the criteria just presented to evaluate the evolution of the lattice parameters across the $L n_{0.5} A_{0.5^{-}}$ $\mathrm{MnO}_{3}$ series, the steady decrease in c is consistent with 

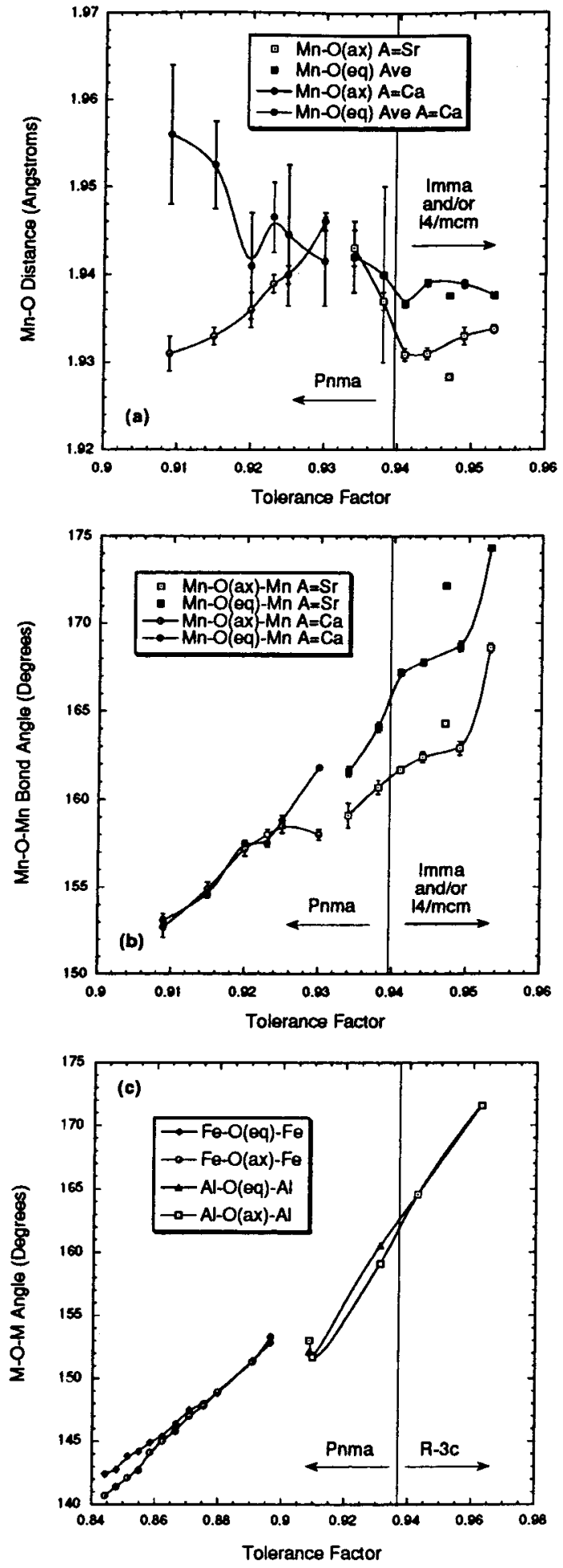

Figure 4. The relationship between $\mathrm{Mn}-\mathrm{O}$ distances, $\mathrm{Mn}-$ $\mathrm{O}-\mathrm{Mn}$ bond angles, and the tolerance factor (calculated using nine coordinate radii for the A-site cations). Part (a) shows the evolution of the $\mathrm{Mn}-\mathrm{O}(\mathrm{ax})$ bond lengths and the average of the two $\mathrm{Mn}-\mathrm{O}(\mathrm{eq})$ bond lengths. The identities of $\mathrm{O}(\mathrm{ax})$ and $\mathrm{O}(\mathrm{eq})$ are defined in ref 48. Part (b) shows the evolution of the $\mathrm{Mn}-\mathrm{O}-\mathrm{Mn}$ angles. Part (c) shows the bond angle evolution found in the $\mathrm{LnFeO}_{3},{ }^{49}$ and $\mathrm{LnAlO}_{3}{ }^{80-83}$ series. Lines are intended as guides for the eye. Among the $\mathrm{Ln}_{0.5} \mathrm{Sr}_{0.5} \mathrm{MnO}_{3}$ compounds, the values for $\mathrm{Pr}_{1 / 2} \mathrm{Sr}_{1 / 2} \mathrm{MnO}_{3}$ fall outside of the expected trends, as briefly discussed in the text.

an increase in the octahedral tilting distortion in response to the decreasing radius of the Ln/A cations,
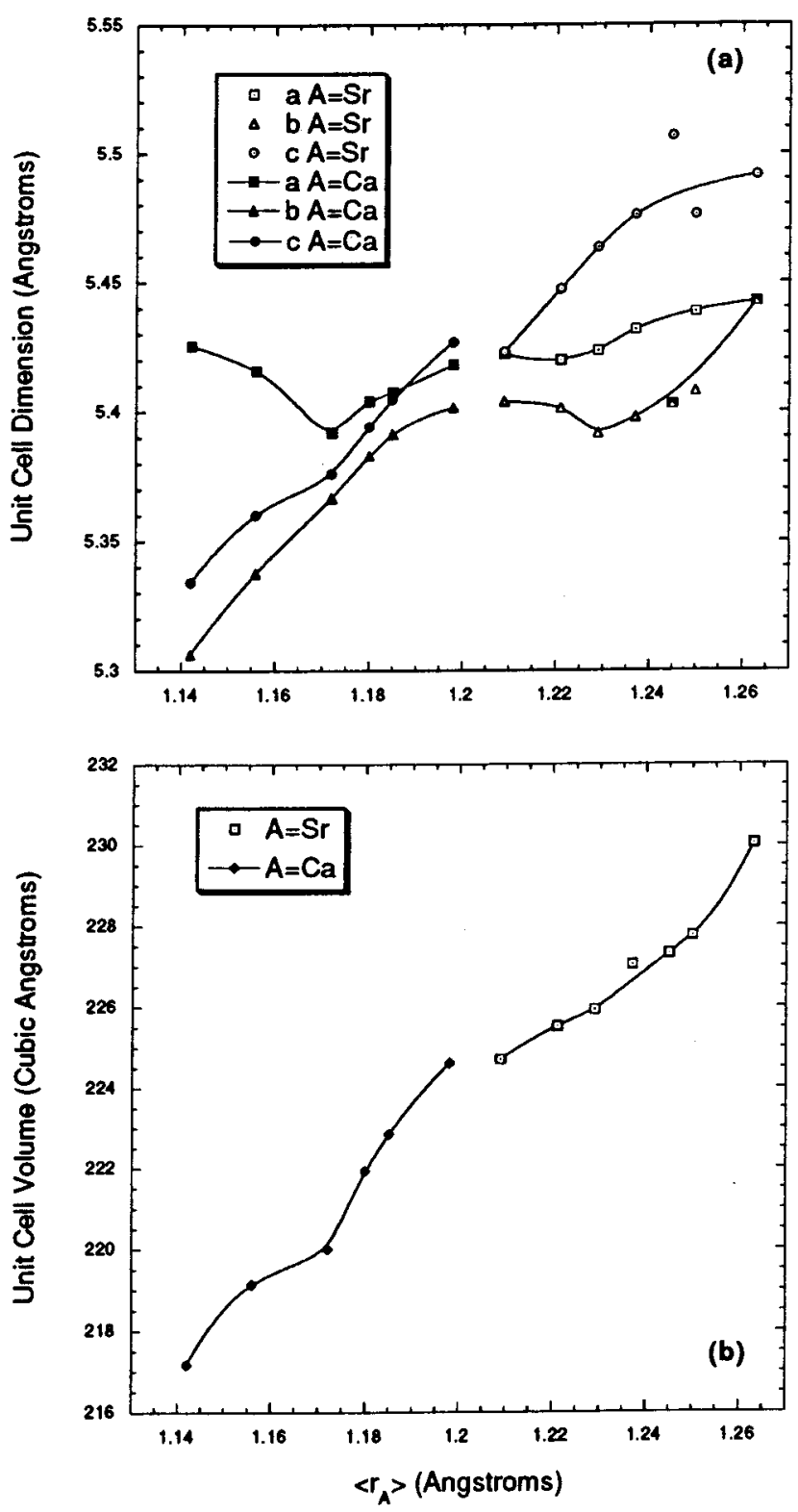

Figure 5. Variations in (a) the lattice parameters and (b) the unit cell volume as a function of $\left\langle r_{A}\right\rangle$. Lines are included merely as guides for the eye.

whereas the upturn in a for $\mathrm{Ln}_{0.5} \mathrm{Ca}_{0.5} \mathrm{MnO}_{3}$ compounds, with lanthanides smaller than $\mathrm{Nd}$, signals the presence of orbital ordering at room temperature. This conclusin is completely consistent with the trends in the $\mathrm{Mn}-\mathrm{O}$ distances. Two additional features in Figure $5 a$ merit comment. The upturn in $b / \sqrt{2}$ for the last two members of the $\mathrm{Ln}_{0.5} \mathrm{Sr}_{0.5} \mathrm{MnO}_{3}$ series $(\mathrm{Ln}=\mathrm{Gd}, \mathrm{Sm})$ corresponds to an increase in the $\mathrm{Mn}-\mathrm{O}(\mathrm{ax})$ distance (Figure $4 a)$ and a change in space group, driven by a change in the octahedral tilt system, from Imma to Pnma. Finally, b/ $\sqrt{2}$ is less than a or c across the entire series, suggesting some degree of orbital ordering throughout. However, for $\mathrm{La}_{0.5} \mathrm{Ca}_{0.5} \mathrm{MnO}_{3}$ and the entire $\mathrm{Ln}_{0.5} \mathrm{Sr}_{0.5}$ $\mathrm{MnO}_{3}$ series, $\mathrm{c} \geq \mathrm{a}$, contrary to expectations for both the $\mathrm{O}$ and the $\mathrm{O}^{\prime}$ distortion. This effect is also seen in $\mathrm{PrNiO}_{3}, \mathrm{LaTiO}_{3}, \mathrm{LaGaO}_{3}$, and $\mathrm{LaCrO}_{3} .{ }^{51}$ The origin of this effect is a distortion of the $\mathrm{O}(\mathrm{eq})-\mathrm{Mn}-\mathrm{O}(\mathrm{eq})$ angles

(51) Lacorre, P.; Torrance, J . B.; Pannetier, J .; Nazzal, A. I.; Wang, P. W.; Huang, T. C. J . Solid State Chem. 1991, 91, 225. 

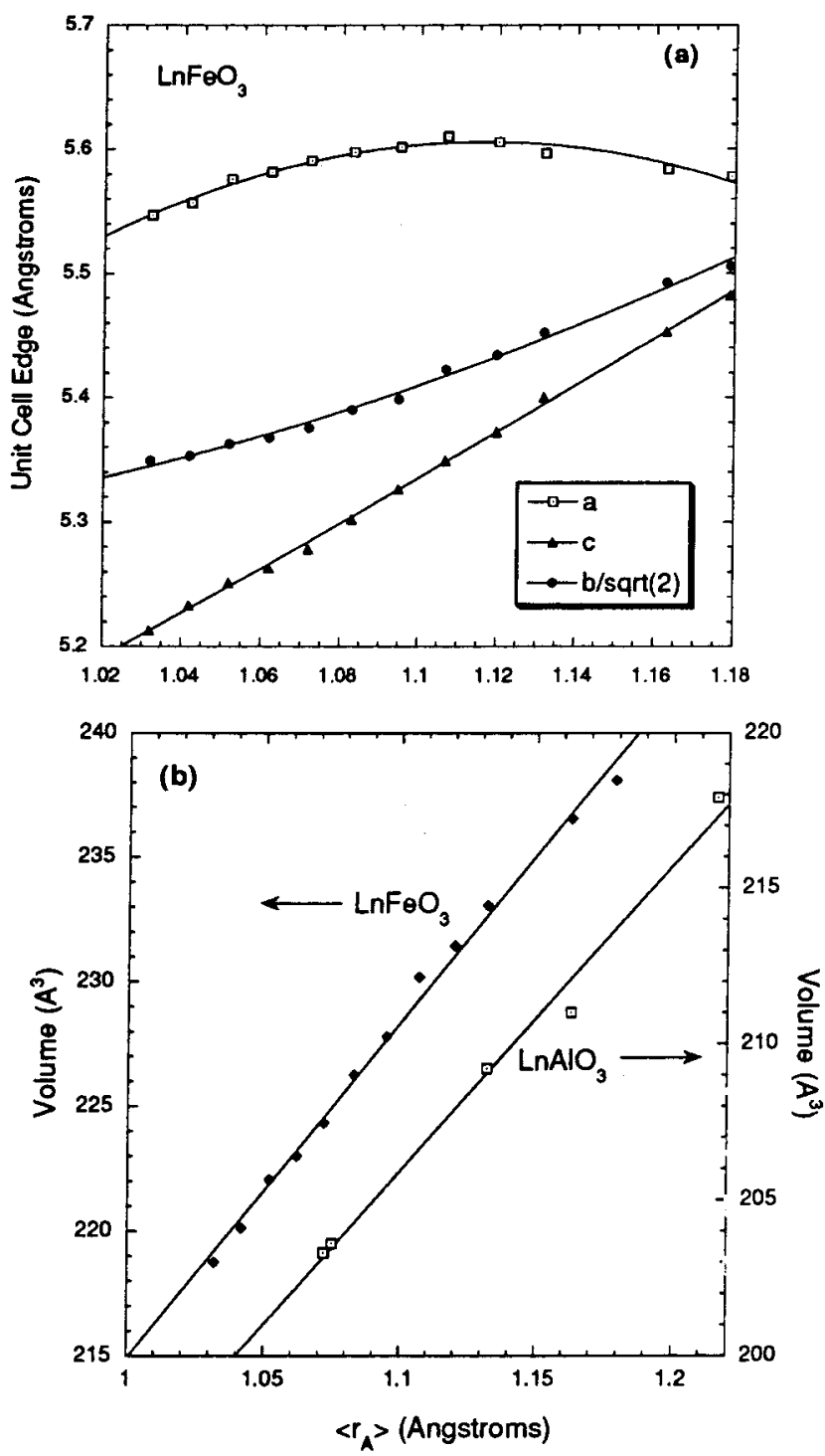

Figure 6. Variations in (a) the lattice parameters and (b) the unit cell volume as a function of $\left\langle\mathrm{r}_{\mathrm{A}}\right\rangle$ for $\mathrm{LnFeO}_{3}$ compounds in part (a) and both $\mathrm{LnFeO}_{3}$ and $\mathrm{LnAlO}_{3}$ compounds in part (b). Lines in part (a) are included as guides for the eye, and in part (b) the lines represent the linear relationship between $\mathrm{V}$ and $\left\langle r_{A}\right\rangle$ expected from Vegard's law.

of the octahedron, which lie roughly in the ac plane. These angles are $90 \pm \beta^{\circ}$, with $\beta$ consistently close to $1^{\circ}$. It can be geometrically shown that in the absence of octahedral tilting or $\mathrm{J} T$ distortions, this distortion of the octahedra affects the lattice parameters in the following manner

$$
\begin{aligned}
& \mathrm{a}=\mathrm{a}_{\mathrm{u}}\left[\sqrt{2} \cos \left(45^{\circ}+\beta / 2\right)\right] \\
& \mathrm{c}=\mathrm{c}_{\mathrm{u}}\left[\sqrt{2} \sin \left(45^{\circ}+\beta / 2\right)\right]
\end{aligned}
$$

where $a_{u}$ and $c_{u}$ are the lattice constants for a structure with perfect octahedra. For $\beta=1^{\circ}$, the lattice constants become $a=(0.991) a_{u}$ and $c=(1.009) c_{u}$. This result corresponds to an expansion in c and a contraction in a of $\sim 0.05 \AA$ in each direction. These changes are sufficient to account for the observation $c \geq a$. However, the strong contraction in c that accompanies the octahedral tilting distortion eventually leads to structures with $c<a$.
Unlike $\mathrm{LnFeO}_{3}$ and $\mathrm{LnAlO}_{3}$ (Figure 6b), the unit cell volume of the $\mathrm{Ln}_{0.5} \mathrm{~A}_{0.5} \mathrm{MnO}_{3}$ (Figure $5 \mathrm{~b}$ ) series deviates significantly from Vegard's law. This fact is almost certainly a consequence of the nonequivalent ionic radii of the lanthanide and alkaline-earth cations. Consider the hard sphere model on which ionic radii are based. If the A-site were randomly populated by rigid spheres of two different sizes, then the lattice would contract until it fully contacted the larger sphere, leaving the smaller sphere to rattle around in a cavity appropriately sized for the larger cation. In such a model, the distortion of the lattice would depend only on the size of the larger cation. Of course, in actuality, ions are not rigid spheres, as evidenced by the steady contraction in volume with decreasing $\left\langle\mathrm{r}_{\mathrm{A}}\right\rangle$. However, the nonlinearity of the contraction clearly illustrates the fact that the approximation of randomly distributed ions with an effective ionic radius $\left\langle r_{A}\right\rangle$ is not strictly valid either. In general, as the polarizability of the larger A-site cation decreases, it will behave more like a rigid sphere. The large polarizability of $\mathrm{Sr}^{2+}$ is critical for the formation of $\mathrm{Sr}_{0.5} \mathrm{Ln}_{0.5} \mathrm{MnO}_{3}$ compounds with the smaller lanthanides. Calcium is a less polarizable ion, but $\mathrm{Ca}_{0.5^{-}}$ $\mathrm{Ln}_{0.5} \mathrm{MnO}_{3}$ is stable because its ionic radius is much closer to the radii of the lanthanide ions.

Octahedral Tilting. All of the compounds studied in this work are distorted from the ideal cubic perovskite structure by octahedral tilting. Across the entire $\mathrm{Ln}_{0.5} \mathrm{~A}_{0.5} \mathrm{MnO}_{3}$ series, the largest deviation from $90^{\circ}$ observed in the $\mathrm{O}-\mathrm{Mn}-\mathrm{O}$ angles is $1.2^{\circ}$. There is some distortion in the $\mathrm{Mn}-\mathrm{O}$ distances, driven by J T effects, but with the exception of $\mathrm{Sm}_{0.5} \mathrm{Ca}_{0.5} \mathrm{MnO}_{3}$ and $\mathrm{Sm}_{0.25} \mathrm{Y}_{0.25}$ $\mathrm{Ca}_{0.5} \mathrm{MnO}_{3}$, the $\mathrm{Mn}-\mathrm{O}$ distance distortions are rather small. So to a good approximation, one can consider tilting of essentially rigid octahedra to be the primary distortion mechanism and cooperative J T distortions as the secondary distortion mechanism. Glazer ${ }^{52}$ devised a system of notation for describing octahedral tilting distortions in perovskites by specifying the magnitude and phase of the octahedral rotations about each of the Cartesian axes. ${ }^{53}$ For a detailed description of this notation, works by Glazer 52,54 or more recently by Woodward ${ }^{55}$ should be consulted.

All of the $\mathrm{Ln}_{0.5} \mathrm{Ca}_{0.5} \mathrm{MnO}_{3}$ compounds studied as well as $\mathrm{Gd}_{0.5} \mathrm{Sr}_{0.5} \mathrm{MnO}_{3}$ and $\mathrm{Sm}_{0.5} \mathrm{Sr}_{0.5} \mathrm{MnO}_{3}$ adopt structures with Pnma space group symmetry. This distortion is a consequence of octahedral tilting described by the three tilt system $a^{-} b^{+} a^{-}$, and is most commonly associated with the $\mathrm{GdFeO}_{3}$ and/or $\mathrm{CaTiO}_{3}$ structures. If the inphase rotations about the b axis are eliminated, the twotilt system $a^{-} b^{0} a^{-}$is obtained. This tilt system also gives an orthorhombic unit cell, but the space group symmetry now becomes I mma rather than Pnma. The structures of $\mathrm{Nd}_{0.25} \mathrm{Sm}_{0.25} \mathrm{Sr}_{0.5} \mathrm{MnO}_{3}$ and $\mathrm{Nd}_{0.5} \mathrm{Sr}_{0.5} \mathrm{MnO}_{3}$ are consistent with $a^{-} b^{0} a^{-}$octahedral tilting. Finally, elimination of the rotations about a axis produces the one-tilt system $\mathrm{b}^{0} \mathrm{~b}^{0} \mathrm{a}^{-}$(more commonly written $\mathrm{a}^{0} \mathrm{a}^{0} \mathrm{c}^{-}$). This tilt system leads to a structure that belongs to the tetragonal space group I $4 / \mathrm{mcm}$. The three compounds

(52) Glazer, A. M. Acta Crystallogr. 1972, B28, 3385

(53) The Cartesian axes are defined so that in the cubic structure they run along the 4-fold axes parallel to the $\mathrm{Mn}-\mathrm{O}$ bonds.

(54) Burns, G.; Glazer, A. M. Space Groups for Solid State Scientists, 2nd ed. Appendix A9-6; Academic: Boston, 1990.

(55) Woodward, P. M. Acta Crystallogr. 1997, B53, 32. 

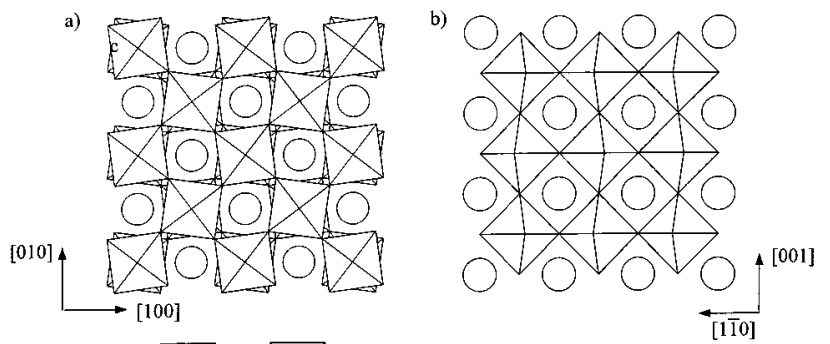

c)

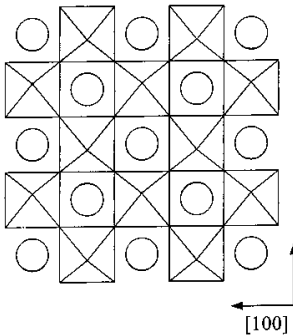

d)

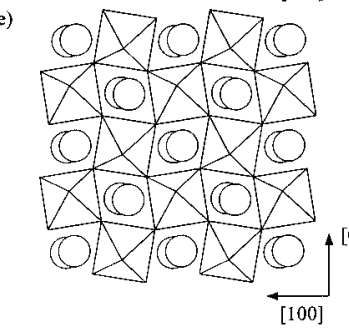

$\left.\right|_{f)} ^{[001]}$
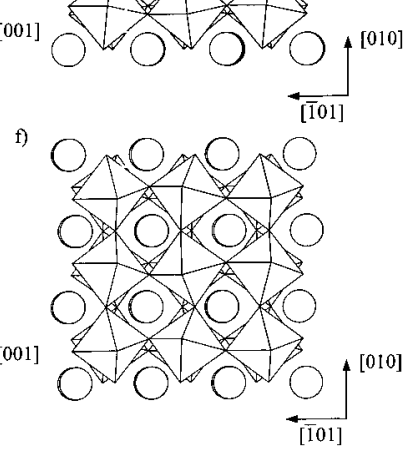

Figure 7. The structure of $\operatorname{Pr}_{0.5} \mathrm{Sr}_{0.5} \mathrm{MnO}_{3}\left(14 / \mathrm{mcm}, \mathrm{a}^{0} \mathrm{a}^{0} \mathrm{C}\right)$ looking down (a) [001] and (b) [110], $\mathrm{Nd}_{0.5} \mathrm{Sr}_{0.5} \mathrm{MnO}_{3}$ (I mma, $\left.\mathrm{a}^{-} \mathrm{b}^{0} \mathrm{a}^{-}\right)$looking down (c) [010] and (d) [101], and $\mathrm{Sm}_{0.5} \mathrm{Ca}_{0.5^{-}}$ $\mathrm{MnO}_{3}$ (Pnma, $\mathrm{a}^{-} \mathrm{b}^{+} \mathrm{a}^{-}$) looking down (e) [010] and (f) [101]. In these polyhedral representations of the structure, each octahedron symbolizes a manganese at the center of the octahedron and oxygen ions at each vertex. The round circles represent the Ln/A ions.

with the largest $\left\langle\mathrm{r}_{\mathrm{A}}\right\rangle$ values, $\mathrm{La}_{0.17} \mathrm{Nd}_{0.33} \mathrm{Sr}_{0.5} \mathrm{MnO}_{3}, \mathrm{Pr}_{0.5^{-}}$ $\mathrm{Sr}_{0.5} \mathrm{MnO}_{3}$, and $\mathrm{La}_{0.5} \mathrm{Sr}_{0.5} \mathrm{MnO}_{3}$, were found to contain large coherent domains of both $14 / \mathrm{mcm}$ and Imma symmetry. The I mma structure was the majority phase $(87 \%)$ in $\mathrm{La}_{0.17} \mathrm{Nd}_{0.33} \mathrm{Sr}_{0.5} \mathrm{MnO}_{3}$, whereas the $14 / \mathrm{mcm}$ structure was more prevalent in $\mathrm{Pr}_{0.5} \mathrm{Sr}_{0.5} \mathrm{MnO}_{3}$ (85\%) and $\mathrm{La}_{0.5} \mathrm{Sr}_{0.5} \mathrm{MnO}_{3}(61 \%)$. The structures of $\mathrm{Sm}_{0.5} \mathrm{Ca}_{0.5}$ $\mathrm{MnO}_{3}$ (Pnma, $a^{-} b^{+} a^{-}$tilting), $\mathrm{Nd}_{0.5} \mathrm{Sr}_{0.5} \mathrm{MnO}_{3}$ (I mma, $\mathrm{a}^{-} \mathrm{b}^{0} \mathrm{a}^{-}$tilting), and $\mathrm{Pr}_{0.5} \mathrm{Sr}_{0.5} \mathrm{MnO}_{3}$ (I4/mcm, $\mathrm{a}^{0} \mathrm{a}^{0} \mathrm{C}$ tilting) are shown in Figure 7 for comparison. The concepts of in-phase (Figures 7b, 7c, and 7e) and outof-phase (Figures 7a, 7d, and 7f) tilting are selfexplanatory from inspection of this figure.

It has long been known that the presence and magnitude of the octahedral tilting distortions could be qualitatively related to the tolerance factor. The value of the tolerance factor is unity when the size of the A cation perfectly matches the cubic $\mathrm{MO}_{3}$ network, and a cubic structure is expected. ${ }^{56} \mathrm{~F}$ or $\mathrm{t}_{12}<1$, the $\mathrm{A}$ cation is too small and it will generally be energetically favorable to undergo octahedral tilting distortions to optimize the $\mathrm{A}-\mathrm{O}$ interactions, but the tolerance factor concept al one does not offer any insight into which tilt

(56) The tolerance factor should be calculated using 12-coordinate radii for the $A$ cation to obtain a scale where $=1$ represents a perfect fit to the $\mathrm{MO}_{3}$ lattice. However, it is much more common in the manganate literature to use 9-coordinate radii for the $\mathrm{A}$ cation because this more closely approximates the coordination of the A cation in the distorted perovskite structure. In this paper, both definitions will be employed; they will be denoted as $t_{9}$ and $t_{12}$. system will be most stable. The energetics that stabilize specific tilt systems have recently been investigated and it has been shown that as the tolerance factor decreases, there is a certain point below which the $a^{-} b^{+} a^{-}$tilt system (orthorhombic, Pnma) becomes the most energetically favorable configuration. ${ }^{35}$ This generally occurs for $t_{12}<0.98\left(t_{9}<0.94\right) .{ }^{57}$ Figure 4 shows that, consistent with other systems, the $L n_{0.5} \mathrm{~A}_{0.5} \mathrm{MnO}_{3}$ series adopts the $a^{-} b^{+} a^{-}$tilt system for $t_{9}<0.94$.

Although stabilization of the $a^{-} b^{+} a^{-}$tilt system for $t_{12}<0.98$ appears to be universal, there is a delicate balance of forces that determines the most stable tilt system immediately above this critical tolerance factor. Examination of structure type versus tolerance factor among known perovskite compositions reveals that four tilt systems are in direct competion: ${ }^{35} \mathrm{a}^{-} \mathrm{a}^{-} \mathrm{a}^{-}$(rhombohedral, R $\overline{3} \mathrm{c}$ ), $a^{0} a^{0} c^{-}$(tetragonal, I4/mcm), $a^{-} b^{0} a^{-}$(orthorhombic, I $\mathrm{mma}$ ), and $\mathrm{a}^{-} \mathrm{b}^{+} \mathrm{a}^{-}$(orthorhombic, Pnma). ${ }^{58}$ Among $\mathrm{LnMO}_{3}$ compounds at room temperature, the rhombohedral $a^{-} a^{-} a^{-}$tilt system is the most stable configuration. Lattice energy calculations show that this result is partially due to the fact that the $a^{-} a^{-} a^{-}$ tilt system optimizes the attractive Coul ombic interaction between ions. This term becomes increasingly important as the effective charge on the A site cation is increased, so that the trivalent oxidation state of the lanthanide ions stabilizes the $a^{-} a^{-} a^{-}$tilt system. ${ }^{35}$ On the other hand, the orthorhombic (Pnma) $a^{-} b^{+} a^{-}$tilt system optimizes covalent $A-O$ interactions and is exclusively observed, regardless of tolerance factor, for $\mathrm{CaMO}_{3}$ compounds. ${ }^{35}$ The tetragonal $\mathrm{a}^{0} \mathrm{a}^{0} \mathrm{C}$ tilt system is not commonly observed for simple $\mathrm{AMO}_{3}$ perovskites, but among $\mathrm{Sr}_{2} \mathrm{MM}^{\prime} \mathrm{O}_{6}$ perovskites it appears to be the tilt system of choice for $0.98<t_{12}<1.01 .{ }^{59}$

Among the four tilt systems just discussed, the $a^{-} b^{0} a^{-}$ tilt system is the least commonly observed. If we limit our search to $\mathrm{AMO}_{3}$ and $\mathrm{A}_{1-x} \mathrm{~A}^{\prime}{ }_{\mathrm{x}} \mathrm{MO}_{3}$ compositions, only a handful of compounds that adopt this tilt system have been previously reported. These compounds are as follows: $\mathrm{PrAlO}_{3}(151-205 \mathrm{~K}){ }^{60} \mathrm{BaPbO}_{3}\left(4 \mathrm{~K},{ }^{61} 298 \mathrm{~K}{ }^{62}\right)$, $\mathrm{BaCeO}_{3}(563-673 \mathrm{~K}),{ }^{63}\left(\mathrm{Pr}_{0.65} \mathrm{Ba}_{0.35}\right) \mathrm{MnO}_{3}(298 \mathrm{~K}),{ }^{64}$ $\left(\mathrm{La}_{0.7} \mathrm{Ba}_{0.18} \mathrm{Sr}_{0.12}\right) \mathrm{MnO}_{3}(1.6 \mathrm{~K}),{ }^{34}\left(\mathrm{La}_{0.7} \mathrm{Ba}_{0.3}\right) \mathrm{MnO}_{3}$ (1.6 $\mathrm{K}),{ }^{34}$ and $\left(\mathrm{Nd}_{0.5} \mathrm{Sr}_{0.5}\right) \mathrm{M} \mathrm{nO}_{3}(298 \mathrm{~K}) .28,41$ The occurrence of this unusual tilt system in $\mathrm{PrAlO}_{3}$ is driven by crystal field stabilization of the 4 electrons on praseodymium. 65 Among the $\mathrm{BaM}^{4+} \mathrm{O}_{3}$ compounds, $\mathrm{BaPbO}_{3}\left(\mathrm{t}_{12}=0.985\right.$,

(57) In the $\mathrm{LnAlO}_{3}$ series, $\mathrm{NdAlO}_{3}\left(\mathrm{t}_{9}=0.943, \mathrm{t}_{12}=0.983\right)$ adopts $\mathrm{a}^{-} \mathrm{a}^{-} \mathrm{a}^{-}$, whereas while $\mathrm{SmAlO}_{3}\left(\mathrm{t}_{9}=0.931, \mathrm{t}_{12}=0.972\right)$ adopts $\mathrm{a}^{-} \mathrm{b}^{+} \mathrm{a}^{-}$ Across the $\mathrm{LnNiO}_{3}$ series, $\mathrm{LaNiO}_{3}\left(\mathrm{t}_{9}=0.950, \mathrm{t}_{12}=1.003\right)$ adopts $\mathrm{a}^{-} \mathrm{a}^{-} \mathrm{a}^{-}$, whereas $\mathrm{PrNiO}_{3}\left(\mathrm{t}_{9}=0.936, \mathrm{t}_{12}=0.981\right)$ adopts $\mathrm{a}^{-} \mathrm{b}^{+} \mathrm{a}^{-}$. In the $\mathrm{Ln}_{0.7} \mathrm{~A}_{0.3} \mathrm{MnO}_{3}$ series, $\left(\mathrm{La}_{0.7} \mathrm{Ca}_{0.13} \mathrm{Sr}_{0.17}\right) \mathrm{MnO}_{3}\left(\mathrm{t}_{9}=0.929, \mathrm{t}_{12}=0.981\right)$ adopts $\mathrm{a}^{-} \mathrm{a}^{-} \mathrm{a}^{-}$, whereas $\left(\mathrm{La}_{0.7} \mathrm{Ca}_{0.17} \mathrm{Sr}_{0.13}\right) \mathrm{MnO}_{3}\left(\mathrm{t}_{9}=0.928, \mathrm{t}_{12}=0.980\right)$ adopts $\mathrm{a}^{-} \mathrm{b}^{+} \mathrm{a}^{-}$. All comparisons were made at room temperature.

(58) Two other tilt systems, $a^{-} b^{-} a^{-}$(monoclinic, 12/a) and $a^{-} b^{0} c$ (monoclinic, I2/m), are also possible, but these correspond to structures intermediate between the four tilt systems discussed in the text. The $a^{-} b^{-} a^{-}$system is intermediate between $a^{-} b^{0} a^{-}$and $a^{-} a^{-} a^{-}$, whereas $a^{-} b^{0} c$ is intermediate between $a^{-} b^{0} a^{-}$and $a^{0} a^{0} c$, as has been previously pointed out (Ritter et al. J . Solid State Chem. 1996, 127, 276).

(59) Woodward, P. M. Ph.D. Dissertation, 1996, Oregon State University, Ch. 5

(60) Burbank, R. D. J . Appl. Crystallogr. 1970, 3, 112.

(61) Thornton, G.; J acobson, A. J . Mater. Res. Bull. 1976, 11, 837.

(62) Cox, D. E.; Sleight, A. W. Proceedings of the Conference on Neutron Scattering (Gaitlinburg, TN) 1976, 1, 45.

(63) Knight, K. S. Solid State I onics 1994, 74, 109.

(64) J irak, Z.; Pollert, E.; Andersen, A. F.; Grenier, J .-C.; Hagemuller, P. Eur. J . Solid State Inorg. Chem. 1990, 27, 421. 
$\left.a^{-} b^{0} a^{-}\right)^{66}$ is intermediate between $\mathrm{BaPrO}_{3}\left(\mathrm{t}_{12}=0.951\right.$, $\left.a^{-} b^{+} a^{-}\right)$and $\mathrm{BaTbO}_{3}\left(t_{12}=0.992, a^{-} a^{-} a^{-}\right),{ }^{67}$ and the series of phase transitions in $\mathrm{BaCeO}_{3}$ with increasing temperature is $a^{-} b^{+} a^{-} \rightarrow a^{-} b^{0} a^{-} \rightarrow a^{-} a^{-} a^{-} \rightarrow a^{0} a^{0} a^{0}$. So, for $\mathrm{BaMO}_{3}$ compounds, it appears that this tilt system is intermediate between the orthorhombic $a^{-} b^{+} a^{-}$ and rhombohedral $a^{-} a^{-} a^{-}$tilt systems. The absence of the $a^{-} b^{0} a^{-}$tilt system among $\mathrm{LnMO}_{3}$ compounds is attributed to the increased charge on the A-site cation, which stabilizes the rhombohedral $a^{-} a^{-} a^{-}$structure with respect to the $a^{-} b^{0} a^{-}$structure.

Among the manganates, which account for more than half of the $a^{-} b^{0} a^{-}$perovskites, there are some inconsistencies to the claim that the $a^{-} b^{0} a^{-}$tilt system acts as an intermediate between $a^{-} b^{+} a^{-}$and $a^{-} a^{-} a^{-}$. The phase diagram for $\mathrm{Ln}_{0.7} \mathrm{~A}_{0.3} \mathrm{MnO}_{3}$ compositions contains all three tilt systems, but the $a^{-} b^{0} a^{-}(I \mathrm{mma})$ portion of the phase diagram is not found in the transition region between the other two tilt systems; rather it occupies the region of large $\left\langle r_{A}\right\rangle$ and low temperature. ${ }^{68}$ This region is also that of the phase diagram where the mismatch in ionic radii between the lanthanide and the alkaline earth cations is the largest. A large size mismatch between A-site cations is also present in $\left(\mathrm{Pr}_{0.65} \mathrm{Ba}_{0.35}\right) \mathrm{MnO}_{3}$ as well as $\left(\mathrm{Nd}_{0.5} \mathrm{Sr}_{0.5}\right) \mathrm{MnO}_{3}$ and the other I mma perovskites reported in this work. We feel this commonal ity is not just coincidenceand proposethat in the doped manganate perovskites, the presence of short-rangelayered $\mathrm{Ln} / \mathrm{A}$ cation ordering is responsible for stabilization of the orthorhombic $a^{-} b^{0} a^{-}(I \mathrm{mma})$ and tetragonal $a^{0} a^{0} c^{-}(14 / \mathrm{mcm})$ tilt systems for tolerance factors $t_{12}>0.98\left(t_{9}>0.94\right)$. Although additional work is necessary to prove this assertion, there are several observations that are consistent with such a conclusion. First of all, layered ordering is the most commonly observed arrangement for long-range ordering of A-site cations. 69 Second, the $\mathrm{Mn}-\mathrm{O}-\mathrm{Mn}$ bond angles are necessarily anisotropic in the $a^{-} b^{0} a^{-}$and $a^{0} a^{0} c^{-}$tilt systems, in each case introducing some two-dimensional character into the structure. This type of distortion is complementary to the planar dimensionality of the layered $\mathrm{Ln}^{3+} / \mathrm{A}^{2+}$ ordering. As a result, variations in the layer spacing necessary to accommodate ordering of large and small cations into alternating layers are not in conflict with the cooperative octahedral tilting distortion. Conversely, the $a^{-} a^{-} a^{-}$tilt system is by symmetry completely isotropic. Therefore, distortions of the oxygen framework that are necessary to stabilize A-site cation ordering are not consistent with the symmetry of this tilt system, in much the same way that cooperative J T distortions are incompatible with the long-range symmetry of the $a^{-} a^{-} a^{-}$tilt system. Further support for this conclusion can be obtained from inspec-

(65) Birgeneau, R. J .; Kjems, J . K.; Shirane, G.; Van Uitert, L. G. Phys. Rev. B 1974, 10, 2512.

(66) There is some debate regarding the room-temperature structure of $\mathrm{BaPbO}_{3}$. Cox and Sleight determined it to belong to tilt system $a^{-} b^{0} a^{-}$(space group Imma), other references report the $a^{-} b^{0} c$ tilt system (I $/ \mathrm{m})$ where the two out-of-phase tilts are no longer equivalent (Ritter, H., et al., Z. Phys. B 1989, 75, 297; Marx, D. T., et al. J . Phys. B Conds. Matter 1992, 46, 1144), which is of course closely related to the $a^{-} b^{0} a^{-}$tilt system.

(67) J acobson, A. J .; Tofield, B. C.; Fender, B. E. F. Acta Crystallogr. B 1972, 28, 956

(68) Radaelli, P. G.; Marezio, M.; Hwang, H. Y.; Cheong, S.-W. J . Solid State Chem. 1996, 122, 444.

(69) Park, J .-H.; Woodward, P. M.; Parise, J . B. Chem. Mater., in press.

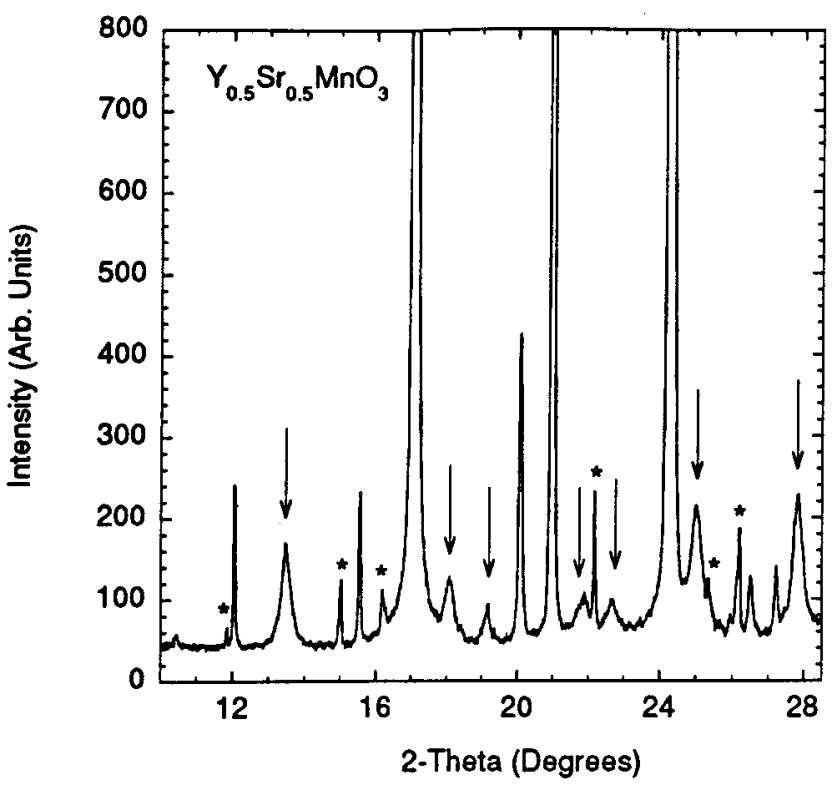

Figure 8. An exploded view of the diffraction pattern for $\mathrm{Sr}_{0.5} \mathrm{Y}_{0.5} \mathrm{MnO}_{3}$. Peaks marked with an arrow are forbidden in Imma but are allowed in Pnma. Peaks marked with an asterisk are impurity peaks arising from the presence of a small amount of $\mathrm{YMnO}_{3}$. All other peaks are allowed in both I mma and Pnma.

tion of the individual peak widths in the diffraction patterns of $\mathrm{Ln}_{0.5} \mathrm{Sr}_{0.5} \mathrm{MnO}_{3}$ perovskites, which adopt the Pnma space group. Those peaks that violate the extinction conditions of I mma but are allowed in Pnma are slightly broadened in $\mathrm{Sm}_{0.5} \mathrm{Sr}_{0.5} \mathrm{MnO}_{3}$. This effect is more pronounced in $\mathrm{Gd}_{0.5} \mathrm{Sr}_{0.5} \mathrm{MnO}_{3}$ and is extremely large in $\mathrm{Y}_{0.5-x} \mathrm{Sr}_{0.5+x} \mathrm{MnO}_{3}(\mathrm{x} \approx 0)$, as shown in Figure 8. The origin of this effect is a decrease in the size of the coherence length of the in-phase tilt about the $b$ axis as the size difference, $r_{S r}-r_{L n}$ increases. Because the driving force for layered cation ordering should increase as the size difference between $\mathrm{Ln}^{3+}$ and $\mathrm{A}^{2+}$ cation increases and the magnitude of the in-phase tilts will also increase as $\left\langle r_{A}\right\rangle$ decreases, a competition between the two distortion mechanisms would help to explain the rapid decrease observed in the long-range coherence of the in-phase tilts. Figure 9 shows the evolution in the magnitude of the out-of-phase tilts and the in-phase tilts as a function of tolerance factor. Note the contrast between the smooth progression of the out-of-phase tilts, present in both I mma and Pnma, and the more turbulent evolution of the in-phase tilt angle. Additionally, the magnitudes of the in-phase tilting and out-of-phase tilting are quite similar when the size mismatch, $\mid r_{A}-$ $\mathrm{r}_{\mathrm{Ln}} \mathrm{l}$, is small. However, when the size mismatch becomes large, a suppression of the in-phase tilt angle is observed. In contrast, the tilt angles in $\mathrm{LnFeO}_{3}$ and $\mathrm{LnAlO}_{3}$, where A-site cation ordering is not possible, are consistently very similar. A final piece of evidence in support of this conclusion is the fact that for $L n_{0.7} A_{0.3^{-}}$ $\mathrm{MnO}_{3}$ compounds, the $a^{-} b^{0} a^{-}$tilt system is seen only at low temperatures, transforming to $a^{-} a^{-} a^{-}$upon warming to room temperature, whereas for $L_{0.5} A_{0.5^{-}}$ $\mathrm{MnO}_{3}$ compounds the $a^{-} b^{0} a^{-}$and $a^{0} a^{0} c^{-}$tilt systems are observed at room temperature and for smaller values of $\left|r_{A}-r_{L n}\right|$. This result is consistent with the fact that the driving force for layered A-site cation ordering will be largest for a 1:1 ratio of lanthanide to alkal ine earth 

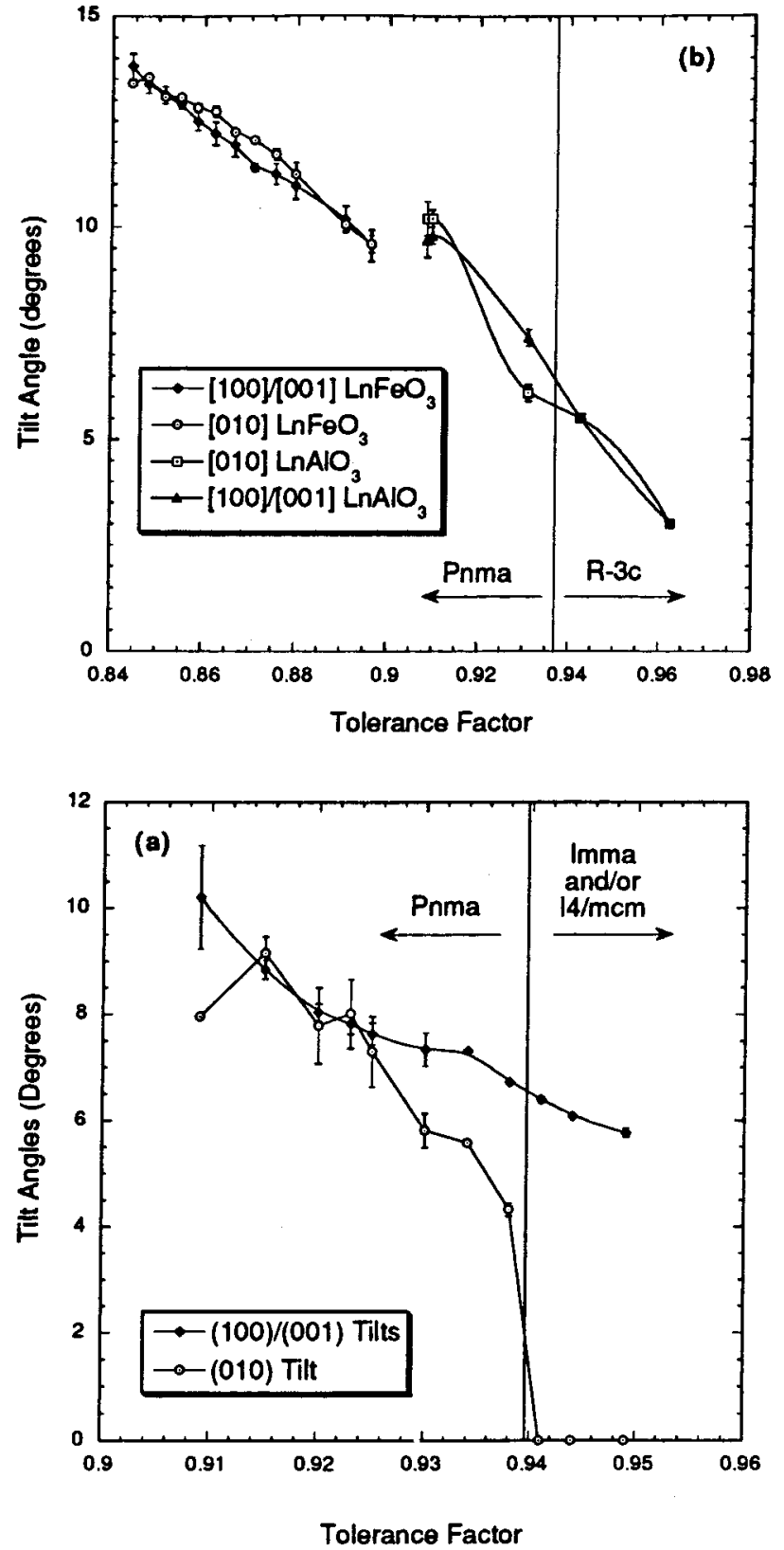

Figure 9. The magnitude of the octahedral tilts, about the Cartesian axes of the cubic structure, for (a) $\mathrm{LnFeO}_{3}$ and $\mathrm{LnAlO}_{3}$ compounds, and (b) $\mathrm{Ln}_{0.5} \mathrm{~A}_{0.5} \mathrm{MnO}_{3}$ compounds belonging to the Imma and Pnma space groups. The in-phase tilt angles were calculated from the oxygen fractional coordinates using the formulas: [010] tilt $=(\{\mathrm{O}(\mathrm{eq}) \mathrm{x}-0.75\} / 0.00427)$ and [010] tilt $=(\{0.25-\mathrm{O}(\mathrm{eq}) \mathrm{z}\} / 0.00452)$, whereas the out-of-phase tilts were calculated with the expressions [100]/[001] tilt $=$ $(-\mathrm{O}(\mathrm{eq}) \mathrm{y} / 0.00440)$ and $[100] /[001]$ tilt $=(\{0.50-\mathrm{O}(\mathrm{ax}) \mathrm{z}\} /$ $0.00888)$. The two values obtained for each tilt angles were then averaged. The error bars represent the difference between the two values. These formulas were derived using the program POTATO. ${ }^{84}$

cations. Whereas all of the evidence presented here in support of short-range $\mathrm{Ln}^{3+} / \mathrm{A}^{2+}$ layered ordering is indirect, taken collectively it strongly supports the hypothesis that such ordering can and does occur. At the very least, this evidence should provide motivation to search for direct evidence either in support of or in contradiction to our assertion.

The diffraction patterns for $\mathrm{La}_{0.5} \mathrm{Sr}_{0.5} \mathrm{MnO}_{3}, \mathrm{Pr}_{0.5} \mathrm{Sr}_{0.5-}$ $\mathrm{MnO}_{3}$, and $\mathrm{La}_{0.17} \mathrm{Nd}_{0.33} \mathrm{Sr}_{0.5} \mathrm{MnO}_{3}$ are unambiguously two phase, each containing an Imma phase $\left(a^{-} b^{0} a^{-}\right.$ tilting) and an $14 / \mathrm{mcm}$ phase $\left(\mathrm{a}^{0} \mathrm{a}^{0} \mathrm{C}^{-}\right.$tilting) and both phases having similar unit cell volumes. The coexistence of two tilt systems in the same sample illustrates the very small energetic differences between these tilt systems. Based on neutron diffraction data, $\mathrm{Pr}_{0.5} \mathrm{Sr}_{0.5^{-}}$ $\mathrm{MnO}_{3}$ has been previously reported to be tetragonal with a space group I $4 / \mathrm{mcm} .{ }^{42,43}$ Thus, the small amount of I mma phase we see in $\mathrm{Pr}_{0.5} \mathrm{Sr}_{0.5} \mathrm{MnO}_{3}$ may be a consequence of small spatial variations in the $\mathrm{Pr}^{3+}: \mathrm{Sr}^{2+}$ ratio. However, increasing the annealing temperature from 1500 to $1510{ }^{\circ} \mathrm{C}$ resulted in the appearance of impurity phases in the sample. Further evidence of the delicate competition between these two tilt systems is the fact that Damay et al. observed Imma domains in electron diffraction patterns of $\mathrm{Pr}_{0.5} \mathrm{Sr}_{0.5} \mathrm{MnO}_{3}$ taken at room temperature, whereas a neutron powder diffraction analysis of the same sample indicated I 4/mcm symmetry. ${ }^{42}$ It is also interesting to note that despite possessing nearly identical tolerance factors, $\mathrm{Pr}_{0.5} \mathrm{Sr}_{0.5} \mathrm{MnO}_{3}$ is predominantly $14 / \mathrm{mcm}$, whereas $L_{0.17} \mathrm{Nd}_{0.33} \mathrm{Sr}_{0.5^{-}}$ $\mathrm{MnO}_{3}$ is mostly I mma. This difference may be caused by the influence of the crystal field stabilization of the $4 \mathrm{f}$ electrons on $\mathrm{Pr}^{3+}$, similar to the structural behavior of $\operatorname{PrAlO}_{3},{ }^{65}$ which adopts tilt systems, $a^{-} b^{0} a^{-}$and $\mathrm{a}^{0} \mathrm{a}^{0} \mathrm{C}^{-}$, not observed among the other $\mathrm{LnAlO}_{3}$ compounds.

The observations detailed in the preceding paragraphs raise some interesting questions. Is the ratio of A-site cations different in the Imma and $14 / \mathrm{mcm}$ phases? If so, is this a consequence of kinetic limitations or does it represent a state of thermodynamic equilibrium? Although our results do not provide conclusive answers to these questions, a few comments are in order. First of all, the unit cell volume of the I mma phase is larger than that of the $14 / \mathrm{mcm}$ phase in all three cases. This result may indicate a slight excess of $\mathrm{Mn}^{3+}$ in the Imma structure, implying either oxygen vacancies or a small enrichment in A-site concentration of the lanthanide ion. Second, even after a subsequent annealing of the $\mathrm{La}_{0.17} \mathrm{Nd}_{0.33} \mathrm{Sr}_{0.5} \mathrm{MnO}_{3}$ sample at 1510 ${ }^{\circ} \mathrm{C}$ for 3 days, the two-phase nature of the sample persisted. The former observation suggests that the two phases have slightly different compositions, as one would expect from the phase rule, whereas the latter observation suggests that the two phases exist in thermodynamic equilibrium.

Structure-Property Relationships. How do the results of this study help to explain the phase diagrams of Figure 1? The evolution of the low-temperature magnetic state for $\mathrm{Ln}_{0.5} \mathrm{Sr}_{0.5} \mathrm{MnO}_{3}$ compounds with decreasing $\left\langle\mathrm{r}_{\mathrm{A}}\right\rangle$ can be understood in the following manner: the anisotropy in the $\mathrm{Mn}-\mathrm{O}-\mathrm{Mn}$ angles in the $14 / \mathrm{mcm}$ space group favors preferential occupation of the $e_{g}$ orbitals in the $\mathrm{MnO}(\mathrm{eq})_{2}$ layers. This preference will favor the AFM-A state, which is observed for $\mathrm{Pr}_{0.5} \mathrm{Sr}_{0.5} \mathrm{MnO}_{3} .{ }^{42,70}$ and apparently $\mathrm{La}_{0.25} \mathrm{Nd} \mathrm{d}_{0.25} \mathrm{Sr}_{0.5} \mathrm{MnO}_{3}{ }^{11} \mathrm{~A}$ crossover to the FMM state is observed for $\mathrm{La}_{0.5} \mathrm{Sr}_{0.5} \mathrm{MnO}_{3}$ because the bandwidth perpendicular to the $\mathrm{MnO}(\mathrm{eq})_{2}$ layers has now increased to the point where the el ectrons become del ocalized in three dimensions.

(70) Kawano, H.; Kajimoto, R.; Y oshizawa, H.; Tomioka, Y.; Kuwahara, H.; Tokura, Y. Phys. Rev. Lett. 1997, 78, 4253. 
Upon cooling, $\mathrm{Nd}_{0.5} \mathrm{Sr}_{0.5} \mathrm{MnO}_{3}$ is known to undergo charge ordering near $160 \mathrm{~K}$, transforming into the AFMCE type structure. ${ }^{28,70}$ Magnetization and resistivity measurements suggest that $\mathrm{Nd}_{0.25} \mathrm{Sm}_{0.25} \mathrm{Sr}_{0.5} \mathrm{MnO}_{3}{ }_{32}$ and $\mathrm{La}_{0.17} \mathrm{Nd}_{0.33} \mathrm{Sr}_{0.5} \mathrm{MnO}_{3}{ }^{11}$ also transform to the chargeordered AFM-CE state at low temperatures. Interestingly, these are the three compounds that display $a^{-} b^{0} a^{-}$ (Imma) octahedral tilting. Figure $4 \mathrm{~b}$ shows that the $\mathrm{Mn}-\mathrm{O}-\mathrm{Mn}$ bond angle anisotropy is retained in these compounds, but that the $\mathrm{Mn}-\mathrm{O}(\mathrm{eq})-\mathrm{Mn}$ angles are markedly smaller than in $\mathrm{Pr}_{0.5} \mathrm{Sr}_{0.5} \mathrm{MnO}_{3}$ and $\mathrm{La}_{0.5} \mathrm{Sr}_{0.5^{-}}$ $\mathrm{MnO}_{3}$. This anisotropy decreases the bandwidth in the $\mathrm{MnO}(\mathrm{eq})_{2}$ layers and leads to complete carrier localization at low temperatures (as evidenced in the resistivity data). As discussed in the Introduction, this carrier localization results in an AFM-CE ground state. Very recent experiments have provided further evidence for the correlation between tilt system and magnetic ground state. Variable temperature neutron and X-ray diffraction measurements show that the $\mathrm{La}_{0.17} \mathrm{Nd}_{0.33} \mathrm{Sr}_{0.5} \mathrm{MnO}_{3}$ sample, which contains both I $\mathrm{mma}$ and $14 / \mathrm{mcm}$ domains at room temperature, transforms to a mixture of AF M-A and AFM-CE states at low temperature.

A change in tilt system $\left(a^{-} b^{0} a^{-} \rightarrow a^{-} b^{+} a^{-}\right)$and in the low-temperature magnetic state (AFM-CE $\rightarrow$ FMM) is once again seen with $\mathrm{Sm}_{0.5} \mathrm{Sr}_{0.5} \mathrm{MnO}_{3}$. The reappearance of the FMM state may seem surprising considering that the $\mathrm{Mn}-\mathrm{O}-\mathrm{Mn}$ angles are becoming increasingly distorted, which is known to decrease $\mathrm{W}$, reduce carrier mobility, and destabilize the FMM state. However, increasing $\langle\omega\rangle$ will also decrease the superexchange stabilization of the AFM-CE state and, perhaps more importantly, there is a sharp decrease in the anisotropy of the $\mathrm{Mn}-\mathrm{O}-\mathrm{Mn}$ bond angles upon going to the $\mathrm{a}^{-} \mathrm{b}^{+} \mathrm{a}^{-}$ tilt system. This latter effect should favor the FMM state because of its 3D character.

The large octahedral tilt angles associated with the $\mathrm{Ln}_{0.5} \mathrm{Ca}_{0.5} \mathrm{MnO}_{3}$ series lead to a decoupling of the charge ordering and Néel temperatures $\left(\mathrm{La}_{0.5} \mathrm{Ca}_{0.5} \mathrm{MnO}_{3}\right.$ is an exception). This phenomenon has been discussed by Kumar and $\mathrm{RaO}^{71}$ who attribute it to increased carrier local ization and a decrease in the superexchange inter-

(71) Kumar, N.; Rao, C. N. R. J . Solid StateChem. 1997, 129, 363.

(72) Poeppelmeier, K. R.; Leonowicz, M. E.; Scanlon, J. C.; Longo, J. M.; Yelon, W. B. J. Solid State Chem. 1982, 45, 71.

(73) Rodriguez-Carvajal, J .; Hennion, M.; Moussa, F.; Moudden, A. H. Phys. Rev. B 1998, 57, 3189.

(74) Karen, P.; Woodward, P. M. J . Solid State Chem., in press

(75) Shannon, R. D. Acta Crystallogr. 1976, A32, 751.

(76) Brown, I. D. J . Appl. Crystallogr. 1996, 29, 479.

(77) Radaelli, P. G.; Cox, D. E.; Marezio, M.; Cheong, S.-W.; Schiffer, P. E.; Ramirez, A. P. Phys. Rev. Lett. 1995, 75, 4488.

(78) Arulraj, A.; Biswas, A.; Raychaudhuri, A. K.; Rao, C. N. R.; Woodward, P. M.; Vogt, T.; Cox, D. E.; Cheetham, A. K. Phys. Rev. B 1998, 57, R8115.

(79) Vogt, T.; Cheetham, A. K.; Mahendiran, R.; Raychaudhuri, A. K.; Mahesh, R.; Rao, C. N. R. Phys. Rev. B 1996, 54, 15303.

(80) Marezio, M.; Dernier, P. D.; Remeika, J . P. J . Solid StateChem. $1972,4,11$

(81) Yu, Y.-D.; Xie, S.-H.; Boysen, H. Wu Li Hsueh Pao 1993, 42, 605.

(82) Diehl, R.; Brandt, G. Mater. Res. Bull. 1975, 10, 85.

(83) Levin, A. A. Kristallografiya 1992, 37, 1020.

(84) Woodward, P. M. J . Appl. Crystallogr. 1997, 30, 206. action with decreasing bandwidth. The latter effect decreases $T_{N}$, whereas the former stabilizes the charge ordered state, increasing $\mathrm{T}_{\mathrm{co}}$. The steady increase in $\langle\omega\rangle$ as $\left\langle r_{A}\right\rangle$ decreases across the $\mathrm{Ln}_{0.5} \mathrm{Ca}_{0.5} \mathrm{MnO}_{3}$ series supports this picture.

\section{Summary}

A systematic study of structural trends as a function of the average radius of the $A$-site cations, $\left\langle r_{A}\right\rangle$, has been carried out in the $L n_{0.5} A_{0.5} \mathrm{MnO}_{3}$ perovskite system. The structural response to a decrease in $\left\langle\mathrm{r}_{\mathrm{A}}\right\rangle$ is an increase in the magnitude of the octahedral tilting distortion. The average distortion of the $\mathrm{Mn}-\mathrm{O}-\mathrm{Mn}$ angles from $180^{\circ}$, $\langle\omega\rangle$, increases proportionally to the decrease in $\left\langle r_{A}\right\rangle$, whereas the average $\mathrm{Mn}-\mathrm{O}$ distance remains essentially constant. This result is in agreement with previous studies of other $\mathrm{LnMO}_{3}$ perovskite systems. However, there are several features of the $\mathrm{Ln}_{0.5} \mathrm{~A}_{0.5} \mathrm{MnO}_{3}$ system that are more complicated than those typically encountered in $\mathrm{LnMO}_{3}$ systems.

When the tolerance factor, $\mathrm{t}_{12}$, is smaller than $\sim 0.98$ $\left(t_{9}<0.94\right)$, the $\mathrm{GdFeO}_{3}$ octahedral tilting distortion (space group $=$ Pnma, tilt system $=a^{-} b^{+} a^{-}$) is observed. This result is also consistent with the behavior observed in other perovskite systems. However, as the tol erance factor increases above 0.98, a transition from Pnma first to I $\mathrm{mma}$ and then to $14 / \mathrm{mcm}$ occurs. This transition corresponds to the elimination first of the in-phase tilting about the $b$ axis, and then the out-of-phase tilting about the $a$ axis $\left(a^{-} b^{+} a^{-} \rightarrow a^{-} b^{0} a^{-} \rightarrow a^{0} a^{0} c^{-}\right)$. The structures that result from the latter two tilting distortions have $\mathrm{Mn}-\mathrm{O}(\mathrm{eq})-\mathrm{Mn}$ bond angles that are significantly larger $\left(4-6^{\circ}\right)$ than the $\mathrm{Mn}-\mathrm{O}(\mathrm{ax})-\mathrm{Mn}$ bond angl es. This difference has important consequences for the carrier transport and magnetic coupling interactions, stabilizing the AFM-A and AFM-CE states with respect to the FMM state. Changes in the roomtemperature space group (Pnma $\rightarrow$ I $\mathrm{mma} \rightarrow I 4 / \mathrm{mcm}$ ) occur at essentially the same values of $\left\langle r_{A}\right\rangle$ at which changes in the low-temperature magnetic state (FMM $\rightarrow$ AFM-CE $\rightarrow$ AFM-A) occur. There is some evidence to suggest that short-range layered A-site cation ordering is responsi ble for stabilizing the I $\mathrm{mma}$ and I $4 / \mathrm{mcm}$ structures over the $\mathrm{R} \overline{3} \mathrm{c}$ structure found over a similar tolerance factor range in $\mathrm{LnMO}_{3}$ systems.

Long-range ordering of occupied $e_{g}$ orbitals and the development of a cooperative J T distortion is evident at room temperature in $\mathrm{Y}_{0.25} \mathrm{Sm}_{0.25} \mathrm{Ca}_{0.5} \mathrm{MnO}_{3}$ and $\mathrm{Sm}_{0.5^{-}}$ $\mathrm{Ca}_{0.5} \mathrm{MnO}_{3}$. Analysis of the $\mathrm{Mn}-\mathrm{O}$ bond lengths suggests a partial confinement of the carriers in the $\mathrm{MnO}($ eq) 2 planes for compounds adopting the I mma and I4/mcm structures.

Acknowledgment. This work was partially supported by the Division of Materials Sciences, U.S. Department of Energy, under contract no. DE-AC02$98 \mathrm{CH} 10886$. The NSLS is supported by the U.S. Department of E nergy, Division of Materials Sciences and Division of Chemical Sciences.

CM980397U 